June 1981

\title{
Effect of Supragingival Plaque Control on the Composition of the Subgingival Microbial Flora in Ligature Induced Periodontitis in the Monkey
}

Beatrice Siegrist

Follow this and additional works at: https://opencommons.uconn.edu/sodm_masters

\section{Recommended Citation}

Siegrist, Beatrice, "Effect of Supragingival Plaque Control on the Composition of the Subgingival Microbial Flora in Ligature Induced Periodontitis in the Monkey" (1981). SoDM Masters Theses. 133.

https://opencommons.uconn.edu/sodm_masters/133 
THE EFFECT OF SUPRAGINGIVAL PLAQUE

CONTROL ON THE COMPOSITION OF THE

SUBGINGIVAL MICROBIAL FLORA IN LIGA-

TURE INDUCED PERIODONTITIS IN THE

MONKEY

\author{
Beatrice Siegrist \\ University of Connecticut \\ School of Dental Medicine \\ Farmington, Conn., 1981
}

\author{
A Thesis \\ Submitted in Partial Fulfillment of the \\ Requirements for the Degree of \\ Master of Science \\ at \\ The University of Connecticut \\ 1981
}




\section{Master of Science Thesis}

THE EFFECT OF SUPRAGINGIVAL PLAQUE CONTROL ON THE COMPOSITION OF THE SUBGINGIVAL MICROBIAL FLORA

IN LIGATURE INDUCED PERIODONTITIS IN THE MONKEY

Presented by

Beatrice Siegrist
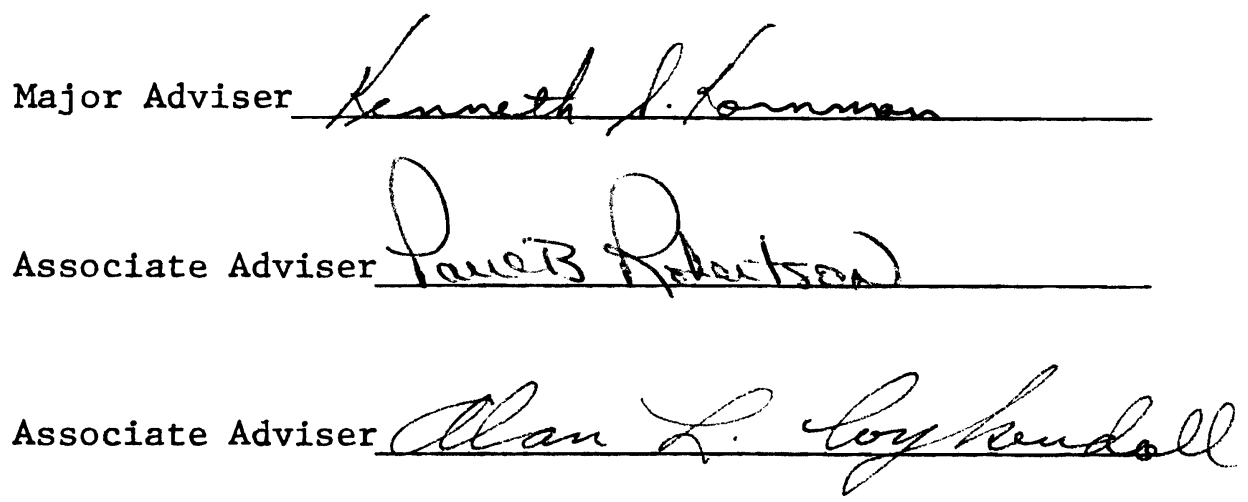

The University of Connecticut

1981 


\section{Acknowledgements}

I would like to thank my major adviser Dr. Kenneth S. Kornman for his assistance and guidance in the completion of this research. Working with him has been a most enjoyable and enlightening experience. I would also like to thank my associate advisers, Dr. Paul B. Robertson for his constructive and extremely helpful criticisms, and Dr. Alan L. Coykendall for serving on my committee. I am extremely grateful to Darlene Jeanetti for her excellent secretarial assistance in typing this thesis and to June Ellis for her competent technical assistance in the laboratory. I would also like to acknowledge the faculty of the Department of Periodontics for their general support and the members of the Center for Laboratory Animal Care for their assistance. Without the help of these individuals, the completion of the study would not have been possible.

My sincerest thanks,

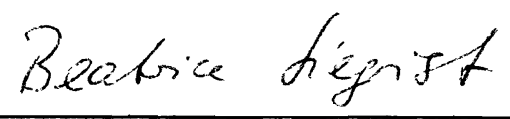

Beatrice Siegrist 
$\begin{array}{lr}\text { List of Tables } & \text { Page } \\ \text { List of Figures } & \mathrm{v} \\ \text { Introduction } & \mathrm{vi} \\ \text { Literature Review } & 2-15 \\ \text { Specific Objectives } & 16\end{array}$

$\begin{array}{ll}\text { Hypothesis } & 17\end{array}$

Materials and Methods 18-26

1. Clinical procedures 18-22

a) assignment of test and control sites 18-19

b) preparation of animals for baseline 20-21 data collection

c) oral hygiene procedures 21-22

2. Microbiological methods 22-26

a) sampling method 22-23

b) diluting and plating 23

c) subculturing and biochemical tests 24-25

d) identification 25-26

Results 27-33

1. Clinical observations 27

2. Microbiological observations 27-33

$\begin{array}{ll}\text { Discussion } & 34-45\end{array}$

Summary and Conclusions 46-47

$\begin{array}{lr}\text { Tables } & 48-57\end{array}$

$\begin{array}{lr}\text { Figures } & 58-71\end{array}$

$\begin{array}{lr}\text { Appendix } & 72-80\end{array}$

$\begin{array}{lr}\text { References } & \text { 81-86 }\end{array}$ 


\section{List of Tables}

Table I:

Predominant cultivable flora in periodontally diseased test sites.

Table II:

Predominant cultivable flora in periodontally diseased control sites.

Table III:

Difference in \% of the total cultivable flora of noncleaned and cleaned sites to baseline data at week 2 and 6 .

Table IV:

BPB: Difference in \% of the total cultivable flora of noncleaned and cleaned sites to baseline data at week 2 and 6 .

Table V: Spirochetes: Difference in \% of the total organisms counted of noncleaned and cleaned sites to baseline data using phase contrast microscopy 


\section{List of Figures}

Figure 1:

Figure 2:

Figure 3:

Figure 4:

Figure 5:

Figure 6:

Figure 7:
Difference in \% of the total cultivable flora of noncleaned and cleaned sites to baseline data at week 2 .

Difference in \% of the total cultivable flora of noncleaned and cleaned sites to baseline data at week 6 .

BPB: Difference in \% of the total cultivable flora of noncleaned and cleaned sites to baseline at week 2 .

BPB: Difference in $\%$ of the total cultivable flora of noncleaned and cleaned sites to baseline at week 6 .

Spirochetes: Difference in \% of the total organisms counted of noncleaned and cleaned sites to baseline data using phase contrast microscopy.

Scatter diagram of the differences in $\%$ of the total cultivable flora of noncleaned and cleaned sites, week 2 .

Scatter diagram of the differences in $\%$ of 
the total cultivable flora of non-cleaned and cleaned sites, week 6 . 


\section{Introduction}

Periodontal disease has been associated with deposits of plaque at the gingival margin and periodontal therapy is directed toward removal of subgingival deposits of plaque and calculus and the control of supragingival plaque. These goals are achieved by means of scaling and root planing, instruction in oral hygiene procedures, periodontal surgery and periodic maintenance. Clinical trials have demonstrated the effectiveness of this combined approach to the treatment of periodontal disease. However, limited information is available concerning the relative effectiveness of individual components of the treatment regimen. Supragingival plaque control, and an initial course of root planing and scaling, has been shown to be effective in controlling an established periodontitis in beagle dogs. This suggests either that supragingival plaque directly causes the disease or that the supragingival plaque influences the subgingival plaque which then would cause the disease. Supragingival plaque control may result in a change of the environment affecting the composition of the subgingival flora. The purpose of this study was to investigate the influence of mechanical supragingival plaque control on the subgingival microflora and clinical parameters of ligature-induced periodontitis in the Cynomolgus monkey. 


\section{Literature Review}

Periodontal disease has long been associated with deposits of plaque at the gingival margin and oral hygiene procedures have been recommended to keep teeth and periodontium in good health for centuries ( $\mathrm{Tal}$ 1980). In 1683 Antoni Van Leeuwenhoek described in a letter to the Royal Society of London how he removed "white matter" from the teeth, mixed it with water and observed many small "living animalcules... which moved very prettily." He strongly advocated oral cleanliness and wrote: "...also when I rub my gums with hard salt, they will not bleed." Two hundred years later, in 1890, Miller compared pyorrhea alveolaris to suppurative processes in general and stated: "...various bacteria may participate in it, just as in suppurative processes not only one, but generally vartous species have been found...". For the treatment of this condition he recommended a "...thorough cleansing of the roots of the teeth, which in all cases anyways advanced can be performed only after making an incision in the gums over and parallel to the root". He also advocated the use of astringents and antiseptics and emphasized that: "the patient must pay the strictest attention to his mouth...". Thus the basic principles of periodontal therapy, including oral cleanliness and control of local etiological factors, were established at the beginning of this century. It was not until the last 20 to 30 years that several studies provided evidence that supragingival plaque accumulations 
were a critical factor in the initiation and progression of periodontal disease. Epidemiological studies in the late 1950's investigated the efficiency of oral hygiene procedures and its relationship to periodontal disease. Lövdal, Arno and Waerhaug (1958) characterized oral hygiene as effective when no soft deposits could be found on any of the surfaces accessible to the toothbrush. Oral hygiene was considered as not effective if some of these surfaces were covered with soft deposits. Using this rather gross system for assessing the quality of oral hygiene, the authors reported a correlation between the efficiency of supragingival plaque control and the incidence and distribution of subgingival calculus, gingivitis and pathologically deepened pockets. Gingivitis and pockets occurred most frequently interproximally and on lingual surfaces, areas not easily accessible to the toothbrush. Using the same criteria for evaluation of oral hygiene efficiency, Schei et al (1959) also found a correlation between increased bone loss and decreased efficiency in supragingival plaque removal. In a later epidemiological study by Greene (1963) more sophisticated indices such as the simplified Oral Hygiene Index (OHI-S, Greene and Vermillion 1964) and the Russell Periodontal Index (Russel 1956) were applied. In all age groups examined, the increasing OHI-S paralleled the Periodontal Index confirming the results of Lövdal, Arno and Waerhaug (1958) and Schei et al. (1959). The development of more precise indices during the early 1960's allowed a better evaluation of the relationship between plaque and periodontal 
disease. Results reported by Ash, Gitlin and Smith (1964) suggested a high positive correlation between the degree of plaque and the degree of gingivitis present. Clear evidence for the hypothesis of the association of supragingival plaque accumulation with gingivitis was given by Löe, Theilade and Jensen (1965). Starting from a state of gingival health, all participants developed gingivitis 10 to 21 days following the elimination of oral hygiene procedures. After reinitiation of supragingival plaque control the gingiva returned to a healthy condition. Evidence that dental plaque was responsible for the development of gingivitis as well as periodontitis was provided in animal models (Lindhe, Hamp and Lö̀ 1973, Lindhe, Hamp and Löe 1975). Twenty beagle dogs were placed on a soft diet and gingival health was established. All oral hygiene procedures were then withdrawn in the experimental group. Signs of subclinical and clinical gingivitis occurred after one month. Periodontitis with loss of attachment and a decreased bone level occurred over a 4-year experimental period. Periodontal lesions were found only on sites which went through the stages of subclinical and clinical gingivitis. In control animals gingival health could be maintained over the 4-year period simply by means of daily supragingival plaque removal. Th1s strong evidence for the causal role of dental plaque in the disease progression from gingivitis to periodontitis also suggests that prevention of the disease may be achieved by means of mechanical elimination of supragingival plaque. This has been confirmed in a 3-year 
clinical trial by Axelsson and Lindhe (1978), in which the effect of controlled oral hygiene procedures in adults were investigated. The test group was on an intensive recall schedule and showed no loss of attachment at the end of the experimental period. The control group obtained no oral hygiene instructions, was maintained on a yearly recall for check-ups and showed signs of gingivitis and loss of attachment. Antimicrobial elimination of supragingival plaque has also been shown to alter the disease process. Rinses with $10 \mathrm{ml}$. of a $0.2 \%$ solution of chlorhexidine gluconate twice daily prevented plaque formation and the development of gingivitis (Löe and Schiött 1970) and topical application of an antibiotic such as Kanamycin improved the oral health of institutionalized Down's Syndrome patients (Loesche and Nafe 1973).

Based on these observations, conventional periodontal therapy is directed toward removal of subgingival deposits of plaque and calculus and the control of supragingival plaque. These goals are usually achieved by means of scaling and root planing, instruction in oral hygiene procedures, periodontal surgery and periodic maintenance. In recent years a few well designed clinical trials have demonstrated the effectiveness of this combined approach to the treatment of periodontal disease (Ramfjord et al 1975, Knowles et al. 1979). However, limited information is available concerning the relative effectiveness of individual components of the treatment regimen. In addition, it is clear that a certain level of oral hygiene is indispensable for successful periodontal therapy 
(Nyman, Rosling and Lindhe 1975). Patients who were treated for periodontal disease were given oral hygiene instructions and were then recalled every 6 months for conventional scaling. A matched group of patients was treated with the same surgical procedure but was recalled every 2 weeks for scaling and root planing. The first group showed a significant loss of clinical attachment and recurrence of the pathologically deepened pockets in an experimental period of 2 years. The group recalled every 2 weeks presented with only minimal signs of gingivitis and no recurring pathologically deepened pockets. In a later study (Nyman, Lindhe, Rosling 1977), the same authors showed that any surgical technique used for pocket elimination was ineffective in the presence of supragingival plaque.

Various studies evaluated the effect of periodic prophylaxis and oral hygiene instructions on the gingival and periodontal tissues. Lightner et al. (1971) attempted to define the optimum frequency for preventive treatment measures consisting of removal of calcified deposits and polishing, and for reinforcing oral hygiene instructions. Experimental and control groups were on various schedules for preventive periodontal treatments and instructions in toothbrushing. During the first two years, all participants showed improvement in gingival health with the group on the most intensive schedule showing significantly more improvement than the others. Interestingly enough, there were no significant changes in Periodontal Index scores for any of the treatment groups during the whole study period. The 
authors interpreted this fact as an expression of the chronic character of the disease. Considering the low initial periodontal indices, it might as well mean that the majority of the participants in this study started with gingivitis which, in patients with an average age of 20 , was not progressing into periodontitis at the time of the experiment. Suomi et al. (1971) tested the hypothesis that, after initial prophylaxis, the progression of gingivitis into periodontitis was retarded by maintaining a high oral hygiene level. Experimental and control groups were brought to a state of complete oral cleanliness at the start of the experiment. The control group was examined yearly and received minimal information on oral hygiene and prophylaxis, whereas the members of the experimental group obtained personal oral hygiene instructions and prophylaxis at 2, 4, 6 and 9 months and every 3 months during the second year. Increased oral cleanliness and less attachment loss for the experimental group were the general findings. The number of teeth with attachment loss greater than $2 \mathrm{~mm}$. over the 3 year period was 14 out of 1198 in the experimental and 35 out of 1163 in the control group. The difference was very small and should not be over-emphasized, but the study provided evidence for the positive influence of careful supragingival plaque removal on gingivitis. The above findings were generally confirmed by a well designed trial by Axelsson and Lindhe (1978). Members of the experimental group obtained instructions in proper oral hygiene techniques and were given a careful dental prophylaxis 
including scaling and root planing every 2 months for two years and every 3 months for the third year. In this group only minor signs of gingivitis were present, and no attachment loss was evident as opposed to the control group who was seen once a year and received regular dental care consisting of the treatment of occurring carious lesions. These studies all provide good evidence that regular dental prophylaxis in combination with excellent oral hygiene slows or even stops the rate of attachment loss and reduces gingivitis significantly.

Some limited information on the effect of prophylaxis alone or oral hygiene alone on gingivitis and clinical attachment is also available. Chawla, Nanda and Kapoor (1975) reported a significant decrease of gingivitis in all experimental groups of 14 and 17 year old children, independent of the frequency of oral hygiene instructions and prophylaxis rendered. Even in the group which obtained instructions in proper toothbrushing techniques only, inflammation of the gingiva was significantly reduced when compared with the control group which received no treatment and no instructions at all. Yet two prophylactic treatments a year without education in supragingival plaque removal appeared to be superior to fust oral hygiene instructions twice a year. The removal of calculus appeared to be directly correlated with the improvement of periodontal health, whereas the removal of bacterial plaque only showed no such trend. This is compatible with the correlation between subgingival deposits and gingivitis 
scores reported earlier (Ramfjord 1961). If all subgingival and supragingival deposits are removed repeatedly every 6 months, the quality of supragingival plaque control appears to influence the incidence of gingivitis significantly as shown by Lövdal et a1. (1961). During a 5-year period the incidence of gingivitis was evaluated in relation to the quality of the patients oral hygiene. A markedly greater decrease in the incidence of gingivitis in all age groups was observed in patients with good oral hygiene as compared to patients presenting with fairly good or not good supragingival plaque control. In a three year longitudinal study on beagle dogs presenting with moderate periodontitis, Morrison et al. (1979) showed that, after initial scaling, attachment levels could be maintained with supragingival plaque removal three times a week, whereas repeated root planing and scaling every 6 months without regular supragingival plaque control retarded the loss of clinical attachment and the increase in pocket depth, but did not prevent it. These findings support the involvement of supragingival plaque in the initiation and progression of periodontal disease. If supragingival plaque control is effective in controlling an established periodontitis as suggested by Morrison et al. (1979) then this suggests either, that supragingival plaque directly causes the disease or that supragingival plaque influences the subgingival plaque. The latter has been argued by Waerhaug (1977). Examining extracted teeth of patients presenting with juvenile periodontitis, Waerhaug observed a 
constant distance of $1.1 \mathrm{~mm}$. between the most apical part of the epithelial attachment and plaque. This was interpreted as a cause and effect relationship with plaque as the cause. As a mechanism for continuing attachment loss Waerhaug proposed a constant forward movement of the subgingival plaque, $4-5 \mu$ per day. The speed of advancement of subgingival plaque was thought to depend on the capacity of some plaque components to synthesize cementing substances, to proliferate in a mainly apical direction and on the efficiency of the host defense mechanisms. A very localized inflammation caused by this forward movement would not be noticeable to the clinician in case of "total supragingival plaque control". In case of complete subgingival plaque removal "total supragingival plaque control" had to be maintained in order to prevent new down growth of plaque. By Waerhaug's definition, a healthy gingival pocket had to be sterile (1978). Any remnants of subgingival plaque left after root planing and scaling would give rise to the formation of new plaque within the pocket and cause further attachment 1oss, the speed of which would be unpredictable. In addition to down growth of the supragingival plaque as described by Waerhaug (1977) there are other theoretical means by which the supragingival plaque may influence the subgingival flora. It has been shown that in the mouth and in other parts of the human body different sites provide distinct environments for a specific microflora. The composition of this microflora is determined by physicochemical factors such as $\mathrm{pH}$ and available oxygen, nutrients and the ability of certain 
microorganisms to adhere to a specific surface. The oxidation reduction potential (Eh) has been shown to be a measure for anaerobiosis and availability or nonavailability of oxygen. In a study on the Eh of developing plaque (Kenney and Ash 1969), a drop of the Eh over time corresponding to a change from an aerobic to an anaerobic environment could be found. This was in agreement with a similar population shift reported previously by Ritz (1967). He isolated mainly aerobic organisms from early plaque as opposed to mainly anaerobic organisms isolated from 7 day old plaque. Kenney and Ash (1969) also found a significantly lower Eh and therefore a more anaerobic environment in periodontal pockets as compared to gingival sulci. It is obvious that such a physical change in the environment has an influence on the ecology of the bacterial population present. A lower Eh will favor the cultivation of faculative and anaerobic organisms. It is also easy to imagine that with scaling and root planing, oxygen is introduced into the periodontal pocket which would render the survival of established anaerobic organisms in this ecological niche difficult and would produce a shift to a more aerobic and facultative subgingival flora. Other than physicochemical properties the availability of certain nutrients in a particular site may act as a selection factor for certain organisms. Microorganisms are able to survive only if their nutritional requirements are fulfilled. Many organisms benefit from or are dependent on preformed organic compounds found in host secretions. A good illustration of this host 
dependence is Treponema dentium which requires alpha-2-globulin for its growth. Alpha-2-globulin is readily available in the gingival crevice. The crevicular fluid contains sufficient amounts of alpha-2-globulin among other serum factors and hemin. Hemin and Vitamin $\mathrm{K}$ are required growth factors for Bacteroides melaninogenicus species. Vitamin $\mathrm{K}$ is produced by other microorganisms present in the gingival crevice area such as Veillonella $\underline{\text { alcalescens }}$ and certain anaerobic streptococci and diphteroids (Loesche 1968). In addition to being host dependent Bacteroides melaninogenicus species therefore also require a microbe- microbeinteraction which is confirmed in the fallure to establish these microorganisms in germfree animals as shown by Gibbons, Socransky and Kapsimalis (1964). Physicochemical and nutritional interactions in a microbial ecosystem are plentiful and just a few are known at this point in time. To explain sufficiently why only certain types of bacteria establish in the gingival crevice area, the ability of microorganisms to attach to certain surfaces has to be accounted for as well (Gibbons and Van Houte 1975). Data from Slots and Gibbons (1978) suggested that $\underline{B}$. melaninogenicus ss. asaccharolyticus and probably other Gram-negative organisms mainly adhere to and colonize Gram-positive bacteria present in dental plaque. If adherence of Gram-positive bacteria could be controlled in both, supragingival and subgingival sites, their colonization with potentially pathogenic Gram-negative organisms could be reduced to a nonpathogenic level. 
Taking the above complex interactions into account, a direct association of supragingival plaque with periodontal disease appears rather unlikely. From the current knowledge it seems that specific variations in one or more ecological parameters may result in a favorable environment for a specific organism or a group of specific organisms present in low numbers in the oral environment at all times. Under favorable conditions these organisms are able to proliferate and out-number the species commonly occurring in high numbers during health. Subsequently periodontal disease may develop. Therefore the ability of supragingival plaque control to influence periodontal disease would most probably result from a change in the environment affecting the subgingival flora.

The present study evaluated the effect of mechanical supragingival plaque control on the subgingival microflora and clinical parameters of ligature-induced periodontitis in the Cynomolgus monkey •

The ligature-induced periodontitis model has been frequently used in dogs as well as in monkeys to evaluate the mechanisms involved in the initiation and pathogenesis of periodontal disease. Cotton floss ligatures have been used to study the conversion of established gingivitis into destructive perfodontitis in the dog (Schroeder and Lindhe 1975). Forty-one months after ligature placement, lesions similar to human periodontitis could be observed. Orthodontic elastics placed on anterfor and posterfor teeth of Rhesus monkeys were found to create lesions suitable for 
the study of treatment procedures for periodontitis (Caton and Zander 1975). After 119 days, the bands were removed and healing of the periodontal lesions created was observed. The lesions were not treated and showed no evidence of reversibility of apical migration of the junctional epithelium or alveolar bone loss 3-380 days after band removal. Chronic gingivitis was converted to periodontitis in Squirrel monkeys after placement of silk ligatures (Heijl, Rifkin and Zander 1976). Histological examination of the sites showed periods of acute inflammation associated with ulceration of the epithelium. It was suggested that bone loss in periodontal disease may occur in bursts of osteoclastic activity. Partial repair would then follow an acute episode and a "stable" lesion would be established. Floss Induced periodontitis in Beagle dogs resulted in the loss of one third of the attachment in 180 days (Lindhe and Ericsson 1978). This was concluded to be a function of plaque accumulation. The authors suggested that further studies should be undertaken in order to determine whether the large amount of plaque or a specific group of pathogens were responsible for the reported amount of attachment loss. In an 8 week longitudinal study on experimentally induced periodontal disease in two Macaca arctoides monkeys, Slots and Hausman (1979) reported an initial flora of mainly Gram-positive organisms. Four weeks after placement of three-0 silk ligatures Gram-negative organisms comprised more than $80 \%$ of the flora with Bacteroides

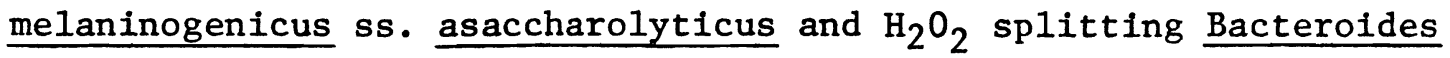
melaninogenicus accounting for $66 \%$ in one and $68 \%$ in the other 
animal. The authors also found a positive relationship between the number of Bacteroides melaninogenicus organisms isolated and alveolar bone 1oss. In a study on the microflora of ligature-induced periodontitis in the Cynomolgus monkey four bacterial stages were found to parallel the clinical parameters (Kornman, Holt and Robertson 1981). In Stage I, which was clinically characterized by chronic gingivitis, Gram-positive organisms comprised $42 \%$ of the total cultivable flora (TCF) and Gram-negative organisms accounted for $5 \%$ with $\underline{B}$. melaninogenicus ss. intermedius as the dominant Gram-negative organism. One to three weeks following ligature placement Stage II was characterized clinically by greater gingival inflammation but no clinical evidence of attachment loss and microbiologically by an increase in surface translocating Gram-negative rods from 6 to 20\% of the TCF. In Stage III radiographic evidence of bone loss was found and the Gram-negative flora increased from $28 \%$ to $61 \%$ of the TCF. B. asaccharolyticus comprised $34.2 \%$ of the TCF and was the dominant Gram-negative cultivable organism. During Stage IV, in week 8 to 17, the clinical parameters showed no change. Gramnegative rods comprised $59.7 \%$ and $\underline{B}$. asaccharolyticus accounted for $17.8 \%$ of the TCF. The shift in the subgingival flora of these monkeys resembled the one reported by Slots (1977) for human periodontitis and ligature induced periodontitis in Cynomolgus monkeys therefore appeared to be an appropriate bacteriological model to study human periodontal disease. 


\section{Specific Objectives}

1) To determine the effect of supragingival plaque control alone on the composition of the subgingival microflora in a site with established disease.

2) To determine the effect of supragingival plaque control alone on the clinical characteristics of established disease. 


\section{Hypothesis}

Supragingival plaque control results in a change in the environment of a complex microbiological ecosystem and thus affects the composition of the subgingival flora of this ecosystem, which then influences the clinical characteristics of a particular test site. 


\section{Materials and Methods}

1. Clinical procedures
a) Assignment of test and control sites
b) Preparation of animals for baseline data collection
c) Oral hygiene procedures

2. Microbiological methods
a) Sampling method
b) Diluting and plating
c) Subculturing and biochemical tests
d) Identification

\section{Clinical procedures}

Four adult Cynomolgus monkeys (Macaca Fascicularis) (3-4 kg) with an intact dentition and completely formed and erupted third molars were obtained from Primate Transports (Port Washington, N.Y.). They were placed in quarantine for six weeks during which time a soft diet (Purina Chow and water) was maintained. At the first examination after quarantine, all animals presented with generalized gingivitis and minimal evidence of periodontitis.

\section{a) Assignment of test and control sites}

In the selection of test and control sites, care was taken to choose opposite sites for test and control groups, to have sites with an interproximal contact area and also to choose teeth that were easily accessible for clinical measurements, 
photographs, radiographs and clinical treatment. The selection of opposite sites for test and control groups allowed for supragingival plaque control to be accomplished on one side of the oral cavity without disturbing the control sites. In addition, any interaction between plaque free and non plaque free sites was thought to be less likely if the control and test teeth were chosen far apart. Based on these criteria the following teeth were used:

$\begin{array}{cll} & \begin{array}{l}\text { Test } \\ \text { Animal \# } 1\end{array} & \text { Contro1 } \\ & 1-4 \mathrm{db} & 2-4 \mathrm{db} \\ & 4-4 \mathrm{db} & 3-4 \mathrm{db} \\ \text { Animal \# } 2 & 1-5 \mathrm{mb} & 2-5 \mathrm{mb} \\ & 4-5 \mathrm{mb} & 3-5 \mathrm{mb} \\ \text { Anima1 \# } 3 & 1-5 \mathrm{mb} & 2-5 \mathrm{mb} \\ & 4-5 \mathrm{mb} & 3-5 \mathrm{mb} \\ \text { Anima1 \# } 4 & 4-5 \mathrm{mb} & 3-5 \mathrm{mb} \\ & 4-7 \mathrm{mb} & 3-7 \mathrm{mb}\end{array}$

For animal 非 1 and 2 a second phase of the experiment was performed. After an initial period of six weeks supragingival plaque control, no oral hygiene procedures were performed for the ensuing 3 to 6 weeks. This was more than enough time for the supragingival plaque to rebuild on the previously cleaned sites. Then the same plaque control procedures were introduced on the former control sites and the former test sites now served as controls. With this cross-over design, a total of 12 control and 12 test sites was obtained. 
b) Preparation of the animals for the baseline data collection

Orthodontic elastics (Unitek Alastik A1, 406-011) were placed around experimental and control teeth by means of a rubberdam clamp forcep and by wedging the teeth slightly apart with a tooth separator. The elastics slipped underneath the gingival margin immediately after they were placed. They were left in place for 6 to 8 weeks until a minimal pocket depth of 3 to $5 \mathrm{~mm}$. was obtained. During that period the animals were examined once a week and the elastics were pushed apically with a curette. On two occasions a missing elastic had to be replaced. After the establishment of the 3 to $5 \mathrm{~mm}$. defects, (measured from the gingival margin) and radiographically evident bone loss, the elastics were removed. The supragingival cleaning was not started until 3 weeks later in animals 非 1, 2 and 4 and 9 weeks later in animal 非 3 . During this time the subgingival and supragingival microbial flora, which was disturbed by the removal of the rubber bands, was allowed to stabilize. At time zero, before plaque control was initlated, baseline microbiological samples were taken and a baseline clinical examination was performed including Plaque Index (Silness and Löe, 1964), Gingival Index (Löe and Silness, 1963), pocket depth measured from the gingival margin, standardized posterior radiographs using custom made bite blocks and a film holder, and clinical photographs. Radiographic evidence of alveolar bone loss was evaluated according to the method of Schei et a1. (1959). Previous studies (Kornman, 
Holt and Robertson 1981) observed increases in surface translocating bacteria and Black Pigmented Bacteroides associated with clinical development of periodontitis (Stage III and IV) in this model. If baseline samples were not consistent with previous findings silk ligatures were tied at the cementoenamel junction (CEJ) and the microflora was monitored until it was consistent with Stage III or IV. Ligatures were then removed for the flora to stabilize and baseline data were obtained 3-7 weeks later.

c) Oral hygiene procedures and time schedule of clinical and microbiological monitoring

After the microbiological and clinical baseline data collection, supragingival plaque control was introduced, 3 times a week for 6 weeks. The test sites were cleaned with rubbercup and pumice. Interdental supragingival plaque control was achieved by means of dental floss. Special attention was given to stay supragingivally with the rubbercup in order not to remove any of the subgingival plaque. The control teeth on the opposite side received no treatment at all. Plaque Index, Gingival Index and pocket depth measurements were obtained at weekly intervals. Microbiological samples, radiographs and clinical photographs were taken at baseline, and weeks 2 and 6 . After the final samples and clinical readings at week 6 , supragingival plaque control was stopped in all animals. 
In animal \# 1 and 非 2 oral hygiene procedures were reinitiated after 4 and 5 weeks respectively, but on the former control sites, whereas the former test sites now served as controls. Again clinical readings were obtained every week and subgingival microbiological samples, photographs and radiographs were taken at weeks 0,2 and 6 .

In order to be able to perform all the above procedures, the animals were anesthetized with Ketamine/Atropine anesthesia, which provided a satisfactory working time of about 30 to 40 minutes.

2. Microbiological methods

a) Sampling method

Subgingival plaque samples were taken with 3 sterile fine paperpoints (Johnson and Johnson, fine sterile absorbent points). To minimize contamination of the paperpoints with supragingival plaque, especially on the noncleaned control sites, a piece of sterile tinfoil was placed at the entrance of the sulcus, between paper point and tooth surface, covering the supragingival plaque. The same procedure was used on the cleaned sites.

The paper points were then placed into the gingival sulcus for ten seconds. After removal the tips were cut off and placed into a glass vial containing $1 \mathrm{ml}$. reduced transport fluid (RTF) without Ethylene-diamine-tetraacetate (Loesche, Hockett, Syed 1972). The vials had been filled with RTF inside the anaerobic 
glovebox, which was maintained under an atmosphere of $5 \%$ carbondioxide and $10 \%$ hydrogen balanced with nitrogen (Aranki et a1. 1969) .

\section{b) Diluting and plating}

After sampling the vials were vortexed for 60 seconds (Vari-Whire mixer, VWR Scientific) and then immediately taken into the anaerobic glove box. A smear was made in order to be able to count the Spirochetes under phase contrast microscopy. Then another $3 \mathrm{ml}$. of $\mathrm{RTF}$ were added to the initial volume of $1 \mathrm{ml}$. Previous experience showed that this allowed us to obtain the right starting concentration of the sample for the further diluting and plating procedures. Prior to further dilution and plating, the samples were sonified for 5 seconds by means of a Kontes sonifier (Kontes Model K 881440). This sonifier has been shown not to damage the Gram-negative anaerobic organisms, some of which are extremely sensitive to sonification (Syed, Loesche, 1978). For the dilution and plating of the samples an automatic diluting and plating device (Spiral Systems, Cincinnati, Ohio) was employed. They were plated on Enriched Trypticase Soy Agar (ETSA, Syed, Svanberg and Svanberg, 1980) a nonselective blood medium enriched with menadione $(1 \mu \mathrm{g} / \mathrm{ml})$ and Vitamin $\mathrm{K}(1 \mu \mathrm{g} / \mathrm{ml})$ to aid growth of anaerobic organisms. Two plates of different dilutions were plated for each sample and were incubated in the anaerobic glove box at $37^{\circ}$ for 5 days. Appropriately diluted plates were then selected for subculturing. 


\section{c) Subculturing and biochemical tests}

Sectors termed either sector III or IV were marked on the surface of each plate with a stainless steel template. Within sector III, $1.7 \times 10^{-3} \mathrm{~m} 1$. of the sample dilution was plated in a spiral pattern. Sector IV included $7.3 \times 10^{-3} \mathrm{~m} 1$. of the sample. The total of colonies within the sector to be counted was evaluated by means of a binocular dissecting microscope. Representative colonies were characterized according to color, shape and circumference, and their frequency was determined. For each sample 1 sector including 20 to 50 colonies was quantitated. The representative colonies of each morphology type were picked and each one subcultured in separate tubes containing Basal Anaerobic Broth (BAB) with 1\% glucose (Syed and Loesche, 1978). After growth in $B A B$, each subculture was streaked on an ETSA plate and checked for purity by means of the dissecting microscope. Pure isolates were then picked into $B A B$ and Basal Esculin Nitrate Broth (BEN) (Loesche, Hockett, Syed, 1972).

For each $B A B$ culture from purity plates aerobic blood plates were streaked and incubated in a candle jar, and a Gram stain was made. A portion of the remaining culture was poured into vials, frozen in liquid nitrogen and stored for Gas Liquid Chromatography (GLC) or further biochemical tests. The last portion was used to determine the $\mathrm{pH}$ by means of a $\mathrm{pH}$-Electrode.

For the BEN cultures the following biochemical tests were completed: Esculin hydrolysis, Nitrate reduction, Indole pro- 
duction and the presence of catalase. All tests were performed as described in the Appendix.

d) Identification

All the results were entered into a Heath Kit 88 computer for storage and identification. The identification routine was set up using schemes derived from Virginia Polytechnic Institute Anaerobe Laboratory Manual (Holdeman, Cato and Moore, 1977; Loesche and Gibbons, 1965, Holmberg and Nord, 1975;

Holbrook, Duerden and Deacon, 1977; Facklam, 1977; Syed and Loesche, 1978; Kornman and Loesche, 1980). Organisms not classifiable by these schemes were grouped according to their Gram stains, their Gram stain morphology and positive or negative growth in the candle jar. They therefore were included in one of the following major groups:

$$
\begin{aligned}
& \text { Gram-positive Cocci, anaerobic or facultative } \\
& \text { Gram-positive Rods, anaerobic or facultative } \\
& \text { Gram-negative Cocci, anaerobic or facultative } \\
& \text { Gram-negative Rods, anaerobic or faculative }
\end{aligned}
$$

For the group of Gram-negative Rods we especially focused on the identification of Bacteroides species, Fusobacterium nucleatum, Surface Translocating Bacteria (STB) and motile Gramnegative rods such as Capnocytophaga, Campylobacter sputorum and Vibrios. 
Bacteroides melaninogenicus ss. intermedius, Bacteroides $\underline{\text { melaninogenicus ss. melaninogenicus and Bacteroides gingivalis }}$ were grouped together as Black Pigmented Bacteroides (BPB). On primary isolation plates, BPB could easily be detected due to their brown pigmentation and their colony morphology. They grow as highly convex and entire colonies, with a diameter of 1 to $2 \mathrm{~mm}$., whereas the also pigmented $\underline{\mathrm{A}}$. odontolyticus appears as a very flat entire colony with a more reddish brown pigment and a diameter of 2-3 $\mathrm{mm}$. when grown on the same blood agar. When possible, BPB isolated were characterized to the species leve1.

Capnocytophaga, Campylobacter sputorum and Vibrios were classified under the general heading of Surface Translocating Bacteria (STB). Colonies were classifled as containing STB based on the colony morphology on primary isolation plates (ETSA), where they grew as brownish translucent colonies which are surrounded by a halo of erosed agar surface. The results were calculated in percent of the total cultivable flora. Also the absolute number of colony forming units (CFU) per sample was calculated. Mean, standard deviation and Student's t-tests for correlated and noncorrelated data were performed in order to detect significant changes of the experimental and control group over time and significant differences between experimental and control groups respectively. 


\section{$\underline{\text { Results }}$}

1. Clinical observations

The mean pocket depth at baseline was comparable in test $(4.6 \pm 1.0 \mathrm{~mm} .$, range $3-6 \mathrm{~mm}$.$) and control (4.2 \pm 0.8 \mathrm{~mm}$., range $3-5 \mathrm{~mm}$. sites. In both groups, $80 \%$ of the sites had a pocket depth of $4 \mathrm{~mm}$. or more. During the 6 week experimental period no changes were observed in these measurements.

The mean Gingival Index of test and control sites at baseline was 2.0 and all the sites showed bleeding on gentle probing. This condition did not change in any of the sites during the 6 week experimental period. The only major clinical change observed was a decrease in the Plaque Index of the test sites as the result of supragingival cleaning. The mean Plaque Index of $1.5 \pm 1.0$ at baseline (range $0.0-3.0$ ) decreased during the experimental period to $0.5 \pm 0.5$ (range $0.0-1.0$ ) and $50 \%$ of the sites were plaque free, whereas $50 \%$ showed a Plaque Index of

1.0. In the noncleaned control sites the mean Plaque Index increased slightly from $1.1 \pm 0.8$ (range $0.0-3.0$ ) to $1.8 \pm 0.8$ (range $0.0-3.0$ ) due to an increased number of sites showing a Plaque Index of 2 or 3 . At week 6 only 2 sites were present with a Plaque Index of 0 or 1 in the control sites.

2) Microbiological observations

No organisms could be recovered from one site at 6 weeks. Therefore this particular site has been excluded and the results 
are presented for 11 test and 11 control sites.

a) Test and control sites at baseline

At baseline, Gram-positive cocci accounted for $13 \%$ of the total cultivable flora (TCF) in the test sites and $17 \%$ of the TCF in the control sites (Table I and II). Facultative, mostly catalase negative organisms predominated in test and control sites. Many of these organisms were esculin positive, variable for indole and nitrate and had a $\mathrm{pH}$ below 6.2. They were classified as Streptococcus mutans/sanguis. Isolates with the same biochemical characteristics but negative for esculin hydrolysis and with a variable $\mathrm{pH}$ (range 4.4-6.8) were compatible with Streptococcus mitior. Anaerobic Gram-positive cocci, accounting for only $3 \%$ of the TCF in cleaned and $2 \%$ of the TCF in non-cleaned control sites (Table I and II) were also predominantly catalase negative. Esculin, nitrate and indole negative organisms with a $\mathrm{pH}>6.2$ were classified as Peptostreptococcus micros whereas organisms with the same biochemical pattern but a $\mathrm{pH}<6.2$ resembled Peptostreptococcus anaerobius. Esculin positive, indole positive but nitrate negative isolates with a terminal $\mathrm{pH}>6.2$ were grouped as Peptococcus asaccharolyticus.

Gram-positive rods comprised $11 \%$ of the TCF in the test sites and $15 \%$ of the TCF in the control sites (Table I and II). Most of the faculative and anaerobic organisms isolated were catalase negative, showed variable results for indole production, esculin hydrolysis, nitrate reduction and $\mathrm{pH}$. These isolates were predominantely Actinomyces but were not classified to the 
species level, except for $\underline{A}$. naeslundii and $\underline{A}$. $\underline{\text { israelii which were }}$ isolated from only 2 different sites.

Gram-negative cocci accounted for $6 \%$ of the TCF in the cleaned sites and $7 \%$ of the TCF in the control sites at baseline, with anaerobic organisms predominating in the cleaned sites and anaerobic and faculative organisms being essentially equal in the control group. Most of the facultative and anaerobic organisms isolated were catalase negative, variable for esculin and negative for indole production and nitrate reduction and were not further classified. Some catalase positive facultative isolates which were nitrate positive, variable for esculin hydrolysis, indole negative and had a $\mathrm{pH} \geq 6.2$ were identified as Neisseria.

Gram-negative rods accounted for the majority of the total cultivable flora, namely $58 \%$ in the cleaned sites and $49 \%$ in the noncleaned control sites at baseline. Facultative Gramnegative rods, accounting for $20 \%$ in the test sites and $12 \%$ in the control sites, were mostly catalase negative, showed variable results in all the other biochemical tests and were not classified to the species level. Anaerobic Gram-negative rods comprised $38 \%$ of the TCF in the cleaned sites and $37 \%$ in the control sites. Of these Black Pigmented Bacteroides (BPB) predominated with $19 \%$ of the TCF in test sites and $13 \%$ in control sites (Table I and II).

Saccharolytic BPB's were isolated from 6 of 11 experimental sites and from 8 of 11 control sites and accounted for $6 \%$ of the 
TCF and $8 \%$ of the TCF respectively. Most frequently they were indole positive, esculin, nitrate and catalase negative, a biochemical pattern compatible with $\underline{B}$. mel. intermedius. One esculin positive, nitrate, indole and catalase negative strain was also recovered and was similar to $\underline{B}$. mel. mel.

From 6 experimental and 5 control sites, asaccharolytic BPB's were recovered and comprised $9 \%$ of the TCF and $4 \%$ of the TCF (Table I and II). Many of these strains were indole positive, esculin, nitrate and catalase negative, had a $\mathrm{pH}>6.2$ in glucose and were similar to $\underline{B}$. gingivalis. A few catalase positive strains were also recovered.

Fusiform Gram-negative anaerobic rods which were esculin, nitrate and catalase negative but produced indole and did not ferment glucose were compatible with Fusobacterium nucleatum. They were recovered from 8 experimental and 9 control sites at baseline and comprised $6 \%$ of the TCF in test and $8 \%$ of the TCF in control sites. Surface Translocating Bacteria (STB) and motile rods were recovered from 4 of the test sites and 8 of the control sites at baseline and accounted for $2 \%$ and $4 \%$ of the TCF. Other Gram-negative anaerobic rods isolated were negative for catalase, nitrate reduction, indole production and varlable for esculin hydrolysis and were generally not fermenting glucose. They were not further classified. 
b) Changes in differences from baseline data over time in noncleaned and cleaned sites

In noncleaned sites, a minor decrease of Gram-positive cocci was found during the 6 week experimental period whereas Gram-positive rods decreased significantly over the 6 week period with a mean difference of $12 \%$ of the TCF at week 2 and $15 \%$ of the TCF at week 6 (Table III, Figs. 1 and 2). This decrease was compensated for by an increase in Gram-negative cocci and rods (Table III, Figs. 1 and 2). Black Pigmented Bacteroides, including isolates which could not be subcultured, F. nucleatum and STB and motile rods all decreased in noncleaned sites at week 2 of the experiment whereas at week $6, \underline{F}$. nucleatum showed an increase of $2 \%$ compared to baseline values (Table III, Figs. 1 and 2 ).

In cleaned sites, a decrease in Gram-positive cocci and rods was observed over the 6 week experimental period, compensated by an increase in Gram-negative cocci. At week 2, Gram-negative rods decreased slightly whereas at week 6 an increase of $4 \%$ was noticed (Table III, Figs. 1 and 2) for which mainly anaerobic organisms other than $\mathrm{BPB}$ and $\underline{\mathrm{F}}$. nucleatum seemed to be responsible (Table 1). A minor increase in STB was also observed over the 6 week period in cleaned sites. Grouping of BPB into asaccharolytic and saccharolytic organisms showed in noncleaned sites an increase of asaccharolytic strains in week 2 followed by a decrease in week 6. Saccharolytic BPB's stayed the same over the initial 2 week period and increased in week 6 (Table IV, Figs. 3 and 4). 
It has to be noted that for this subgrouping of BPB's, all samples where primary isolates could not be subcultured, were excluded. This resulted in a smaller sample size of 6 for the 2 week and 7 for the 6 week samples (Table IV). In cleaned sites a major decrease in asaccharolytic BPB's was found in week 2 and 6 . Saccharolytic BPB again showed no change during the Initial 2 week period and increased at week 6 (Table IV, Figs. 3 and 4$)$. Spirochete counts (\%/200 organisms counted under a phase-contrast microscope) showed an increase in noncleaned sites and a decrease in cleaned sites over the 6 week period (Table V, Fig. 5).

c) Comparison of differences from baseline data of noncleaned and cleaned sites

Using the Student's $t$ test for correlated data, it was found that the changes of the groups of different organisms were the same in noncleaned and cleaned sites over the 6 week experimental period, except for $\mathrm{BPB}$ at week 2 and motile rods at week 6 (Figs. 1 and 2). At week 2 BPB decreased significantly in cleaned sites as compared to noncleaned sites (Fig. 1). Examination of the subgroups of asaccharolytic and saccharolytic BPB showed, that this decrease was mainly due to a larger decrease in asaccharolytic BPB in the cleaned sites as compared to the noncleaned sites, which was significant at week 6 (Fig. 4).

Spirochetes changed in opposite directions in test and 
control group at week 6 (Fig. 5) and, using the Student's $t$-test for uncorrelated data, cleaned sites were found to be significantly different from noncleaned controls. In addition cleaned sites were characterized by a significant decrease in colony forming units (CFU) (Table I) and therefore differed significantly from noncleaned sites which showed no change in CFU (Table II). 


\section{Discussion}

\section{Ligature induced periodontitis}

Periodontitis was induced by means of elastic ligatures. To obtain 3 to $5 \mathrm{~mm}$. defects and a subgingival flora compatible with stage IV, these ligatures were left in place for 8 to 12 weeks. Various types of ligatures have been used previously to induce periodontitis in the animal model. The argument has been made that defects created by elastics exerting pressure on the tissue may be different from defects introduced by silk 1igatures which stay at the gingival margin and accumulate a great deal of bacteria (Slots and Hausmann 1979). Lindhe and Ericsson (1978) concluded in a study on ligature induced periodontitis in beagle dogs, that the ligature must play a role not only for the initiation, but also for the maintenance of destructive periodontitis. Earlier studies in germfree animals supported the importance of microbial activity rather than the effect of a ligature alone in induced periodontitis (Rovin, Costich and Gordon 1966). Schroeder and Lindhe (1980) found that subgingivally placed ligatures produced a trauma-induced ulceration of the junctional epithelium and maintained an acute inflammatory reaction in the beagle dog. Biopsies taken at 21 days after ligature placement showed destruction of supraalveolar connective tissue and coronal portions of alveolar bone. Complete destruction of supraalveolar connective tissue attachment and epithelial down growth were not observed. Also, apical to the cementoenamel 
junction no microbial plaque was noted on the root surface. From this contradictory evidence one can only speculate on the mechanism of induction of periodontal disease in the ligatureinduced periodontitis model.

Various dog studies (Schroeder and Lindhe 1975, Lindhe and Ericsson 1978) suggest that periodontal disease occurs faster when ligatures are placed. The mechanism of Induction might not be that critical. More important is the creation of an environment that allows the growth of certain microorganisms generally associated with periodontal disease. In the case of silk ligatures, this environment may be created primarily by a large bacterial accumulation. Our clinical impression was, that the same amount of bacterial accumulation was not obtained when elastic ligatures were used. Despite that, defects were obtained which were characterized by a microbial composition similar to the one previously reported in the same model but with use of silk ligatures (Kornman, Holt and Robertson 1981). Increased trauma due to pressure on the tissue may produce an irritation factor which exacerbates the bacterially mediated disease. As suggested by Schroeder and Lindhe (1980) tissue ulceration may help to create the appropriate environment for the growth of bacteria generally associated with disease. Many subgingival microorganisms require host products as essentlal nutrients for growth. For example Bacteroides melaninogenicus and Treponema dentium require Hemin and alpha-2-globulin as essentlal growth factors which are 
provided by the host.

In two of our animals, the subgingival microbial flora at the time of band removal was not compatible with the flora of Stage III or IV. The primary isolation plates of these animals contained very few $B P B$ and surface translocating bacteria and were not further processed. All sites in these animals were retied with silk ligatures which were left in place for three weeks. Subsequent samples proved to be compatible with the subgingival microbial flora generally found to be associated with periodontal disease. In all in vivo studies possible differences in host response have to be considered when the results are interpreted. Unfortunately, there are no easily accessible methods available to control this factor which adds a good deal of variability. Baseline samples were obtained 3 to 7 weeks after ligature removal. We had no method to clinically evaluate whether the sample sites were in a state of active or passive disease. The clinical indices presently available only allow us to decide on the presence or absence of the results of disease. Variations observed in the baseline data may be an expression of variations in destructive manifestations, or the time period of 3 to 7 weeks may not have been long enough for the subgingival flora to stabilize. A decrease in the proportions of Gram-positive rods in control as well as in test sites over the six week experimental period may confirm the latter assumption. It also has to be kept in mind that test and control sites were present in each animal 
and that they may have influenced each other and therefore masked the real effect. This is a phenomenon recently observed in non-ligated sites in an animal with ligatures present (Kiel, Kornman and Robertson, in press).

Since the composition of the normal mucosal flora is determined by host defense mechanisms and environmental factors, the baseline flora of different sites and different animals is expected to show variability. For this reason the data were evaluated on a site by site basis in terms of differences from baseline findings. Since this project was designed to determine the impact of treatment on the subgingival flora, data analyzed in terms of changes in the flora appear to offer the greatest information.

\section{Sampling methods}

Loosely attached or unattached Gram-negative organisms in the base of the periodontal pocket and in close proximity to the front of tissue destruction (Listgarten 1976) are generally thought to be involved in the pathology of perfodontal disease. Certain Gram-negative organisms isolated from such areas have been shown to be pathogenic in the gnotobiotic rat model (Irving, Socransky and Tanner 1978). It is reasonable to use a sample technique which would selectively remove these loosely attached organisms from the base of the periodontal pocket. Sterile paper points have been used previously (Van Palenstein 1975). The paper point technique might, therefore, be preferable to the 
use of a curette or scaler, or the use of a barbed broach (Newman and Socransky 1977), insofar as it may select for the organisms in most intimate contact with the crevicular epithelium. The surgical technique as described by Slots (1976) could not be used in a longitudinal study where frequent samples of the same site had to be taken. However, two major shortcomings have to be kept in mind when using the paper point technique. First, contamination of the sample with supragingival plaque is more easily possible than when using the Newman/Socransky device. Second, the paper point appears to have a saturation point which may have a limiting influence on the total count of bacteria obtained. In the present study we attempted to minimize contamination by means of a piece of sterile tinfoil which was placed on the tooth, at the gingival margin. In previous studies (Kornman, Holt and Robertson 1981) the supragingival plaque was carefully wiped off. Since the supragingival plaque played an important role in the control sites of this study, we chose not to wipe it off and to disturb it only as little as possible. Comparison of the baseline data and the data of the control groups with the data from Kornman, Holt and Robertson (1981) and Slots and Hausmann (1979) showed no major differences in the composition of the subgingival microbial flora characteristic for ligatureinduced periodontitis, and therefore, this method appeared to be acceptable. But some contamination of the subgingival sample with supragingival plaque cannot be totally excluded. For a 
cultural study of human experimental gingivit1s(Syed and Loesche 1978) an increase in Gram-positive cocci during the first week of the experiment and an increase of Gram-positive rods, mainly Actinomyces species, at week 3 have been reported. In case of severe contamination of our subgingival samples with supragingival plaque, amounts of Gram-positive rods in control sites should not have changed considerably as compared to the baseline data. Instead, a decrease in Gram-positive rods in cleaned and non cleaned sites was observed (Figs. 1 and 2). The effect of sampling on the composition of the human subgingival microbial flora has been investigated by means of darkfield microscopy (Mousques, Listgarten and Stoller 1980). Changes in the composition of the subgingival microbial flora were observed between day 0 and 3, after which the bacterial proportions were stabilized. The authors suggested that these changes were due to the sampling as well as to changes in oral hyglene habits of the patients and the removal of supragingival deposits prior to sampling. Also the changes from baseline appeared to be within the limits previously reported as typical for periodontally diseased sites (Listgarten and Hellden 1978). In addition it has been shown in the Cynomolgus monkey that samples taken at week 8 from different sites sampled previously at various time periods did not differ from 8-week samples taken from previously unsampled sites (Kiel, R.A., Master of Dental Science Thesis, University of Connecticut, 1981). 
Handling of the samples and recovery of the organisms

Various reports have shown that dispersion of a subgingival sample may influence the viability of certain cells (Manganiello et a1. 1977, Leadbetter and Holt 1974). The sonifier used in this study has been shown to minimally affect the fragile Gramnegative organisms (Syed and Loesche 1978). The viable recovery rate in our laboratory is around 90 to $95 \%$, which indicates that some of the organisms originally present are 1ost. They may be lost due to sonification or due to the lack of unknown growth factors required and missing in the media. Organisms seen by phase contrast microscopy but rarely recovered are some bacteria such as Selenomonas and the medium and small sized Spirochetes. A certain number of organisms recovered on primary isolation plates could not be subcultured and therefore could not be identified. A frequently occurring isolate that at times made up proportions of 15 to $20 \%$ of the TCF was a small convex and entire gray colony. Very often it could not be subcultured. No pattern of occurrence as to control or test sites could be detected. Some other organisms recovered and subcultured could not be classified to the species level and were included in the major groups of Gram-positive or Gram-negative, anaerobic or aerobic organisms. With the improvement of anaerobic culturing techniques additional unknown bacteria have been found and adequate classification schemes are not available in many cases. It was beyond the scope of this study to extend the 
routinely used tests for identification of these organisms since none of them showed a characteristic pattern or occurred frequently enough. With $37 \%$ Gram-negative anaerobic rods, $13 \%$ BPB in the control group and $19 \%$ in the test group at time 0 (Table I and II) the data in this report are comparable to stage IV desscribed by Kornman, Holt and Robertson (1981). But a separation of $\underline{B P B}$ into saccharolytic and asaccharolytic $B P B$ reveals differences. In the baseline samples of test and control group saccharolytic BPB comprised $6.3 \%$ and $8.4 \%$ of the TCF as compared to $1.5 \%$ in stage IV of the above mentioned study. Asaccharolytic BPB accounted for on $1 \mathrm{y} 9.1 \%$ and $3.7 \%$ as opposed to $17.8 \%$. No major change was detected in these proportions as well as in absolute numbers of asaccharolytic and saccharolytic BPB in the control group during the 6 week period. Tanner et al. (1979) found an association of saccharolytic $\underline{B P B}$ with site of minimal inflammation whereas asaccharolytic BPB were associated with sites of moderate to severe inflammation in humans. The difference in proportions of asaccharolytic and saccharolytic BPB in the baseline of test and control sites of the present study compared to previously reported results by Kornman, Holt and Robertson (1981) may be associated with the absence of subgingival ligatures in our study. Ligature induced periodontitis may depend on an ulceration of the junctional epithelium and a resulting acute inflammation maintained by ligature and bacteria present (Schroeder and Lindhe 1980). The possibility of some healing after removal of subgingivally positioned ligatures cannot be excluded and should be 
evaluated in more detail. White and Mayrand (1981) recovered asaccharolytic $\mathrm{BPB}$ in all sites, in increasing proportions with increasing gingival index and pocket depth. B. asaccharolyticus has previously been associated with advanced periodontitis (S1ots 1977a, Spiegel et al. 1979) and was found to be drastically reduced or absent in samples from healthy sites or sites characterized by gingivitis (Slots 1977b, Spiegel et al. 1979, Tanner et al. 1979). Saccharolytic BPB only were detected in gingivitis sites (Spiegel et al. 1979).

Two weeks after initiation of oral hygiene procedures a 5 fold decrease in the proportion of asaccharolytic $\underline{B P B}$, which corresponds to an 18 fold decrease in absolute numbers, and a 3.5 fold decrease in the proportion of saccharolytic BPB, corresponding to a 12 fold decrease in absolute numbers, were found in the test sites. Proportions and absolute numbers in the control sites stayed at about the same level during the 6 week experimental period. Since BPB are generally not present in significant detectable proportions in supragingival plaque, this difference in $\underline{B P B}$ in control and test sites could be interpreted as a shift in the composition of the subgingival flora due to the removal of supragingival plaque. Since asaccharolytic BPB have been associated with sites of moderate to severe inflammation, a decrease in the gingival index may be expected in the test sites, especially since asaccharolytic $\underline{B P B}$ were isolated from only 2 sites after 6 weeks of supragingival plaque control, as 
opposed to 6 sites at baseline. But no clinical changes in pocket depth or gingival index were observed. All sites bled on gentle probing. It has to be kept in mind that the indices used may not allow detection of minor changes in the clinical condition. More sensitive histological methods in combination with clinical and microbiological data might have revealed additional information. But it can also be argued that possible minor changes detectable with histological methods may still be within the pathological range and would therefore not be of clinical importance. Listgarten, Lindhe and Hellden (1978) found no change in clinical and histological parameters of periodontally involved patients after oral hygiene instructions, although a decrease in the plaque score confirmed efficient supragingival plaque removal during the 25 week experimental period. Also no major shifts were found in the proportions of coccoid cells, motile rods and spirochetes. The lack of changes in gingival index and pocket depth in the sites from which no asaccharolytic BPB was recovered may also be explained as follows:

1) The organisms may have been present in extremely low numbers in the sites they were not recovered from and therefore were not detectable by the methods used. They might have been detected with the use of selective media. 
2) Asaccharolytic $B P B$ is unlikely to be the only organism involved in the disease process.

Fusobacterium nucleatum increased 2 fold in the test sites during the experimental period and an almost 4 fold increase was observed in Gram-negative cocci. From the increase of these organisms as well as changes of spirochetes, coccoid cells and motile rods found previously in microscopical studies (Listgarten, Lindhe and Hellden 1978) it is reasonable to assume that a whole variety of organisms is involved in the disease process, some of which we are not even able to culture yet.

In addition, periodontal inflammation may be nonspecific in origin. In other studies in monkeys, gingival inflammation persisted after $\underline{B}$. melaninogenicus was selectively eliminated (Kornman, Caffessee and Nasjleti 1980).

The significant decrease in Colony Forming Units (CFU) in the test sites produced the following changes in actual numbers of the various groups of microorganisms: 6 fold decrease in Gram-positive cocci, 21 fold decrease in Gram-positive rods, 3.8 fold decrease in Gram-negative rods, whereas the absolute number of Gram-negative cocci remained the same. Despite these rather impressive changes, no clinical differences were observed. This non-responsiveness of the local sites to a decrease in the number of various organisms may be as important as the occurring shifts in the composition of the subgingival flora. It seems reasonable to assume that in an already diseased site 
the local resistance to any infectious agent is lowered as compared to a healthy environment. Therefore a smaller stimulus (or fewer bacteria) may be able to maintain the pathologic process. Supragingival plaque control may be the appropriate means for prevention of gingivitis and periodontitis in most instances, but for the treatment of already compromised patients a more rigid approach is needed and the importance of removal of subgingival deposits in combination with supragingival plaque control has been shown in various studies (Morrison et al. 1979, Listgarten, Lindhe and Hellden 1978, Chawla, Nanda and Kapoor 1975). A supragingival cleaning and supragingival scaling every 3 to 6 months without affecting the subgingival flora cannot be expected to interrupt the disease process. Therefore the present study suggests that the periodontitis associated subgingival flora may be altered by supragingival plaque control but not sufficiently to alter clinical signs of disease. It was not determined whether supragingival plaque control prevented further loss of attachment. 


\section{Summary and Conclusions}

In 4 adult female Cynomolgus monkeys periodontitis was induced in 11 sites by means of elastic ligatures. After establishment of a subgingival microbial flora characteristic for disease supragingival plaque control was initiated in the test sites. Supragingival plaque was removed 3 times a week by means of a rubber cup and pumice and the effect of this treatment on the composition of the subgingival flora was evaluated. Subgingival microbiological samples were taken at week 0,2 and 6 of the experiment, were cultured anaerobically and the composition of the total cultivable flora was characterized. Six weeks of supragingival plaque control in the presence of periodontal disease caused in cleaned test sites as compared to noncleaned controls:

1) A significant $(p \leq 0.05)$ decrease in the total cultivable subgingival flora.

2) A significant $(\mathrm{p} \leq 0.05)$ decrease in the proportions of total Black Pigmented Bacteroides and asaccharolytic Black Pigmented Bacteroldes.

3) No change in Gingival Index and pocket depth, despite a reduction in the Plaque Index.

The present study suggests that supragingival plaque control in the presence of periodontal disease may alter the periodontitis assoclated subgingival microflora but not sufficiently alter clinical signs of disease. From these results we are not able 
to draw any conclusions as to whether the disease in the test sites was still active or not and it was not determined whether supragingival plaque control prevented further loss of attachment. 
Table I: Predominant cultivable flora associated with supragingival plaque removal in periodontally diseased test sites.

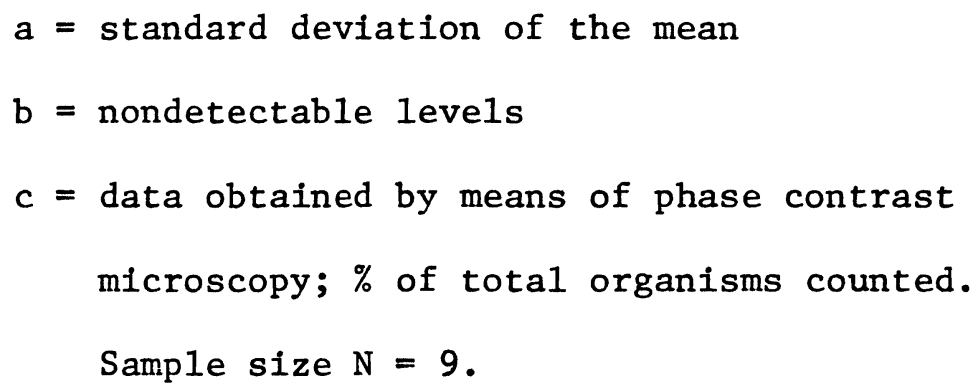




\begin{tabular}{|c|c|c|c|}
\hline \multirow[b]{2}{*}{ Week } & \multicolumn{3}{|c|}{ cleaned } \\
\hline & 0 & 2 & 6 \\
\hline \# Samples & 11 & 11 & 11 \\
\hline AN:FAC Ratio & $3.3\left({ }^{8} 3.8\right)$ & $1.6(18)$ & $4.2(6.9)$ \\
\hline CFU $\left|\times 10^{6}\right|$ & $5.4(3.5)$ & $1.5(1.5)$ & ( 1.5$)$ \\
\hline GRAM+COCCI & $12.7(12.4)$ & $8.4(98)$ & $9.4(9.8)$ \\
\hline Anaerobic & $3.0(4.9)$ & $2.5(4.4)$ & ND ${ }^{b}$ \\
\hline Facultative & $9.7(10.7)$ & $5.9(7.0)$ & $(9.8)$ \\
\hline GRAM+RODS & $11.3(12.0)$ & $3.8(5.9)$ & $3.5)$ \\
\hline Anaerobic & $11.0(12.0)$ & $3.8(5.9)$ & ( 2.5$)$ \\
\hline Facultative & $0.3(0.9)$ & ND & $2.1)$ \\
\hline GRAM-COCCI & $5.9(6.1)$ & $18.0(16.4)$ & $19.3(15.2)$ \\
\hline Anaerobic & $5.3(6.5)$ & $6.5(6.4)$ & $(9.3)$ \\
\hline Facult ative & $0.6(1.7)$ & $11.5(16.3)$ & 110 \\
\hline GRAM-RODS & $57.8(10.5)$ & $55.6(21.0)$ & $(19.8)$ \\
\hline Anaerobic & $37.8(15.1)$ & $29.1 \quad(13.3)$ & $(24.9)$ \\
\hline BPB & $19.3(11.2)$ & $6.3(6.7)$ & ( 9.4$)$ \\
\hline Asacc. & $9.1(11.8)$ & $1.8(3.9)$ & $3.8)$ \\
\hline Sacc. & $6.3(7.6)$ & 2.7 ) & 9.9 ) \\
\hline F. nucleatum & $5.7(5.3)$ & 7.1 (11.6) & ( 9.4$)$ \\
\hline Facultalive & $19.6(12.4)$ & $26.0 \quad(20.8)$ & (13.7) \\
\hline STB+motile rods & $2.4(3.9)$ & $4.0(4.9)$ & 30 \\
\hline SPIROCHETES ${ }^{C}$ & $16.0(10.4)$ & 9.8 & 6.8 \\
\hline
\end{tabular}


Table II: Predominant cultivable flora in periodontally diseased control sites.

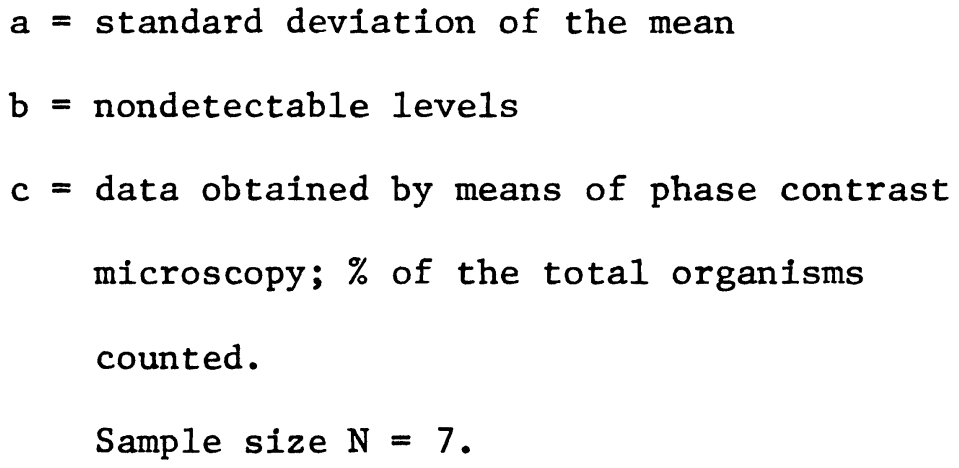




\begin{tabular}{|c|c|c|c|}
\hline \multirow[b]{2}{*}{ Week } & \multicolumn{3}{|c|}{ noncleaned } \\
\hline & 0 & 2 & 6 \\
\hline \# Samples & 11 & 11 & 11 \\
\hline AN:FAC Ratio & $3.0\left({ }^{\mathrm{a}} 3.9\right)$ & $3.6(3.4)$ & ( 1.4 \\
\hline CFU $\left|\times 10^{6}\right|$ & $2.5(2.3)$ & $2.7(1.8)$ & $(25$ \\
\hline GRAM+COCCI & $16.7(19.1)$ & $13.6(17.2)$ & 148 \\
\hline Anaerobic & $1.9(4.0)$ & $1.2(2.7)$ & 1.7 \\
\hline Facultative & $14.8(18.3)$ & $124(17.1)$ & 13.1 \\
\hline GRAM+RODS & $15.3(18.1)$ & $3.8(6.8)$ & $\mathbf{0 9}$ \\
\hline Anaerobic & $6.4(9.2)$ & $1.6(2.4)$ & 0.9 \\
\hline Facultative & $8.9(18.7)$ & 2.2 & ${ }^{b}$ ND \\
\hline GRAM-COCCI & $6.8(5.0)$ & $13.9(13.0)$ & $12 A$ \\
\hline Anaerobic & $3.6(5.7)$ & 10.1 (13.7) & 4.9 \\
\hline Facult ative & $3.2(4.3)$ & 3.8 & 7.5 \\
\hline GRAM-RODS & $49.1(20.1)$ & 55.3 & 54,3 \\
\hline Anaerobic & $37.1(19.3)$ & $42.4(19.1)$ & 41.9 \\
\hline BPB & $12.9(7.7)$ & (10.8) & 12.1 \\
\hline Asacc. & $3.7 \quad(5.2)$ & 9.0) & 1.9 \\
\hline Sacc. & $84 \quad(9.1)$ & $(8.8)$ & $\mathbf{8 . 6}$ \\
\hline F. nucleatum & $7.7(5.0)$ & $(4.1)$ & 9.7 \\
\hline Facultative & $120(13.7)$ & $12.9(21.0)$ & $12 A （ 11.7$ \\
\hline STB + motile rods & $4.1 \quad(3.5)$ & 3.1 & 1.6 \\
\hline SPIROCHETES $^{C}$ & 9.1 & 9.3 & 17.3 \\
\hline
\end{tabular}


Table III: Difference in $\%$ of the total cultivable flora of noncleaned and cleaned sites to baseline data at week 2 and 6 .

$$
\begin{aligned}
a= & \text { standard error of the mean } \\
\boldsymbol{\Psi}= & \text { statistically significant difference to } \\
& \text { noncleaned controls. } \mathrm{p} \leq 0.05, \\
& \text { Student's t-test for correlated data. }
\end{aligned}
$$




\begin{tabular}{|c|c|c|c|c|}
\hline Week & 2 & $\%$ & 6 & \\
\hline & noncleaned & cleaned & noncleaned & cleaned \\
\hline * Samples & 11 & 11 & 11 & 11 \\
\hline $\mathrm{G}+\mathrm{COCCl}$ & $\left.\begin{array}{ll}-3.1 & (6 \\
& (6.5\end{array}\right)$ & $-4.2(4.5)$ & $-2.0(4.4)$ & $-3.2(4.5)$ \\
\hline$G+R O D S$ & $-11.5 \quad(5.8)$ & $-7.5(3.7)$ & $-14.5(5.4)$ & $-9.0(3.5)$ \\
\hline $\mathrm{G}-\mathrm{COCCl}$ & $7.1 \quad(4.4)$ & $12.0(5.4)$ & $5.6(3.8)$ & $13.4(5.2)$ \\
\hline G-RODS & $6.2 \quad(9.1)$ & $-2.2(6.3)$ & $5.2(7.7)$ & $4.0 \quad(5.0)$ \\
\hline F. nucleatum & $-4.6 \quad(1.5)$ & 1.4 (3.6) & $2.0(3.8)$ & $4.4 \quad(4.0)$ \\
\hline STB & $-1.0(1.2)$ & $1.6(2.3)$ & $-2.4(1.6)$ & $0.6^{(1.7)}$ \\
\hline BPB & $-1.3 \quad(4.3)$ & $-13.0^{6}(3.2)$ & $-0.9(3.5)$ & - 9.1 (3.9) \\
\hline
\end{tabular}


Table IV: BPB: Difference in $\%$ of the total cultivable flora of noncleaned and cleaned sites to baseline data at week 2 and 6 .

$a=$ standard error of the mean

( = statistically significant difference to noncleaned controlls. $\mathrm{p} \leq 0.05$,

Student's t-test for correlated data. 


\begin{tabular}{|c|c|c|c|c|}
\hline Week & 8 & . & 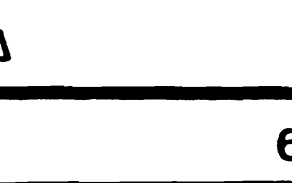 & \\
\hline & noncleaned & cleaned & noncleaned & cleaned \\
\hline \# Samples & 6 & 6 & 7 & 7 \\
\hline BPB & $24 \quad(5.4)$ & $-10.6 \quad(4.5)$ & $2.8 \quad(4.6)$ & -9.8 \\
\hline asacc. & $2.7 \quad(5.9)$ & $-10.5 \quad(5.6)$ & $-2.9 \quad(1.7)$ & $-13.1 \overbrace{}^{\star}(5.2)$ \\
\hline sacc. & $-0.3 \quad(3.2)$ & $-0.1 \quad(2.7)$ & $5.7 \quad(4.7)$ & $3.3(4.2)$ \\
\hline
\end{tabular}


Table V: Spirochetes: Difference in \% of the total organisms counted of noncleaned and cleaned sites to baseline data using phase contrast microscopy.

$a=$ standard error of the mean

\# = statistically significant difference to noncleaned controls $\mathrm{p} \leq 0.05$, Student's t-test for noncorrelated data. 


\begin{tabular}{|c|c|c|c|c|}
\hline Week & & $\mathbf{0}$ & & \\
\hline & noncleaned & cleaned & noncleaned & cleaned \\
\hline \# Samples & 7 & 9 & 7 & 9 \\
\hline SPIROCHETES & $0.2 \quad(3.4)$ & $-6.2(4.2)$ & $8.2(4.2)$ & $-9.2^{\bullet}$ \\
\hline
\end{tabular}


Figure 1: Difference in $\%$ of the total cultivable flora of noncleaned and cleaned sites to baseline data at week 2 .

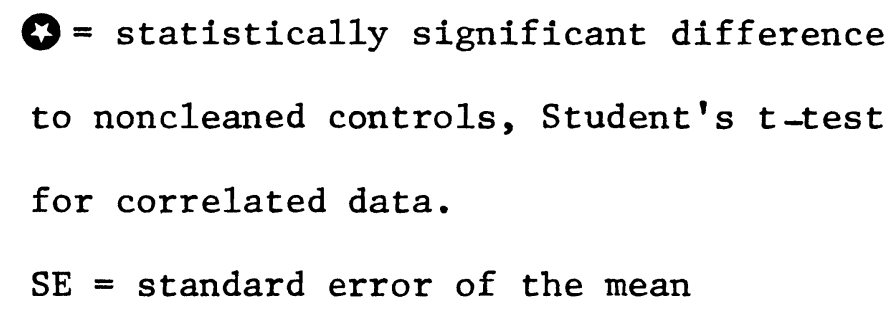




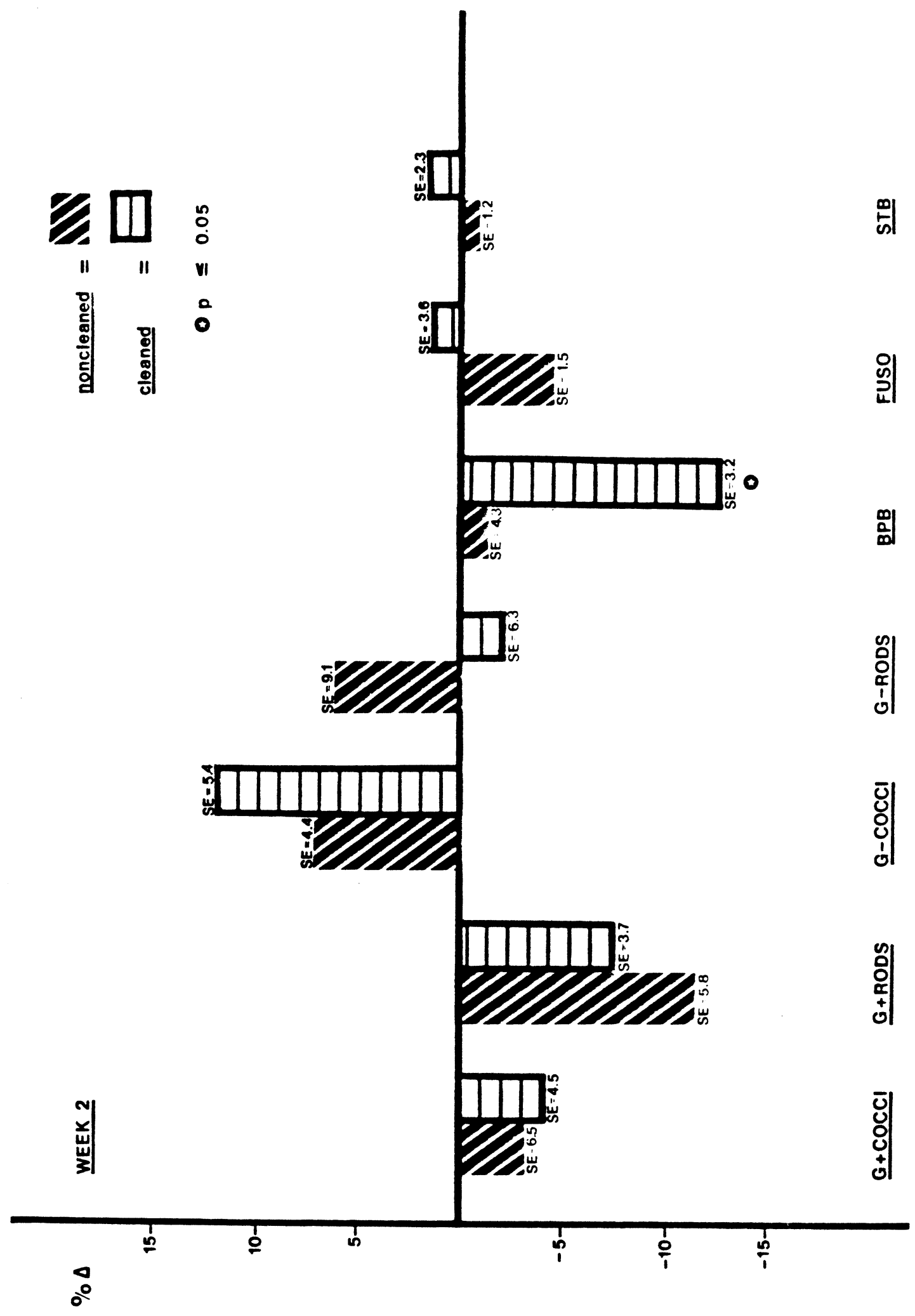


Figure 2: Difference in $\%$ of the total cultivable flora of noncleaned and cleaned sites to baseline data at week 6 .

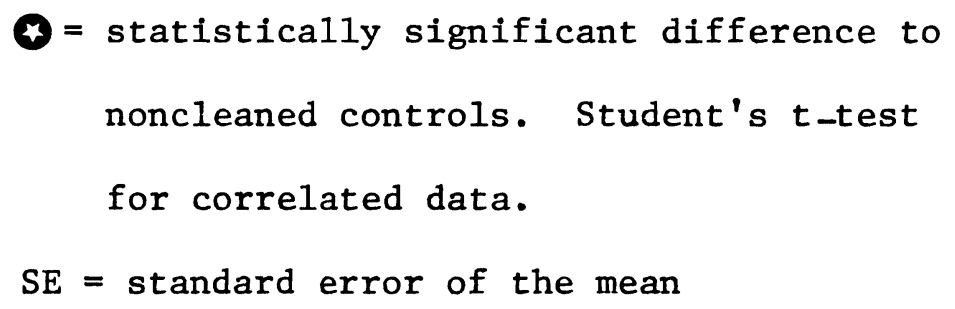




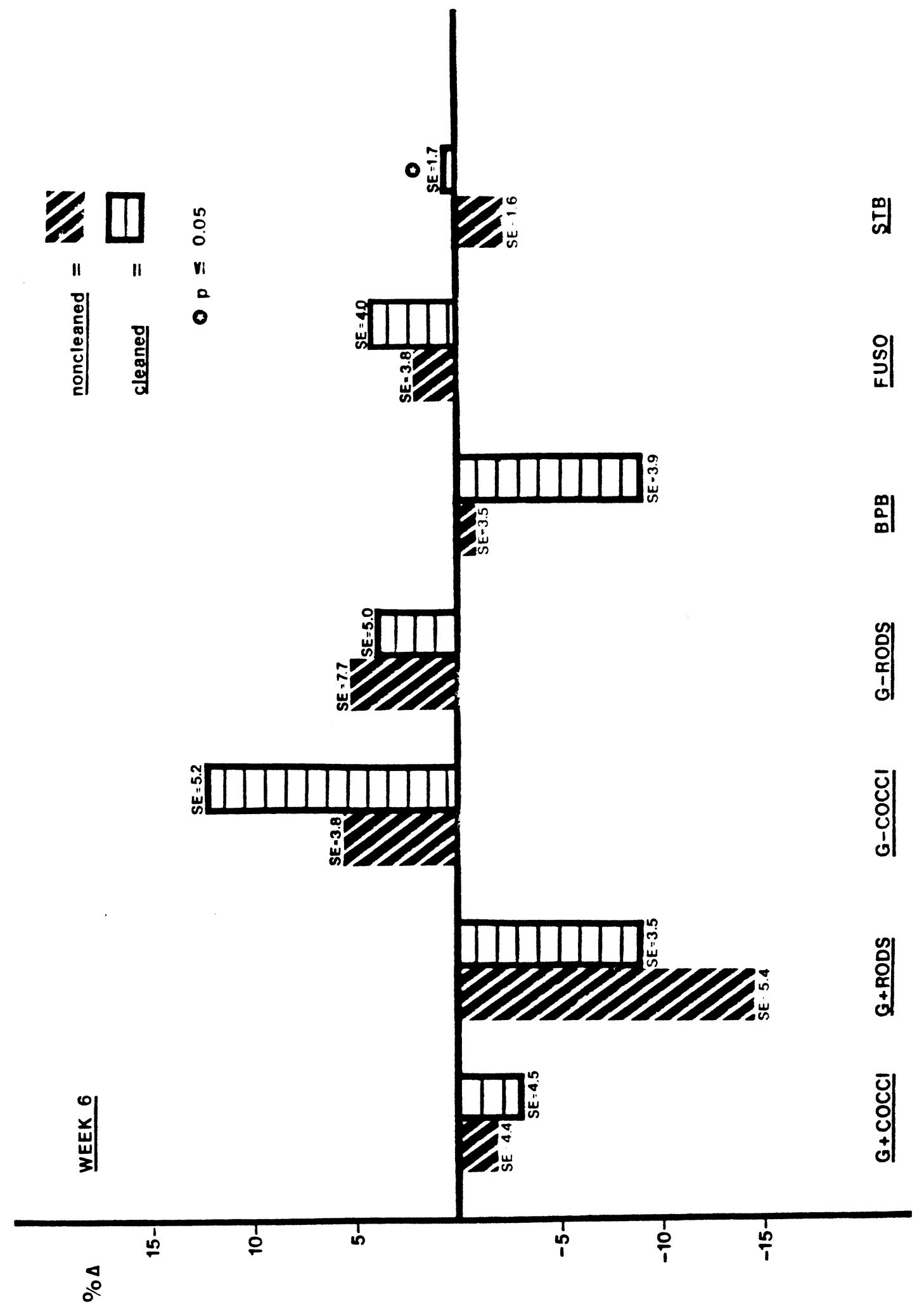


Figure 3: $\mathrm{BPB}$ : Difference in $\%$ of the total cultivable flora of noncleaned and cleaned sites to baseline at week 2 .

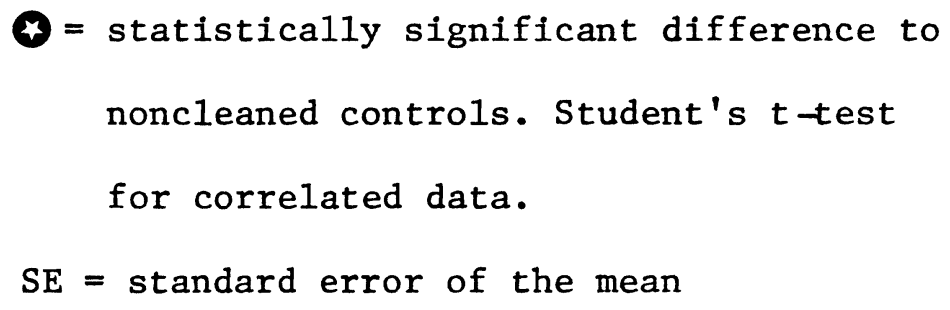




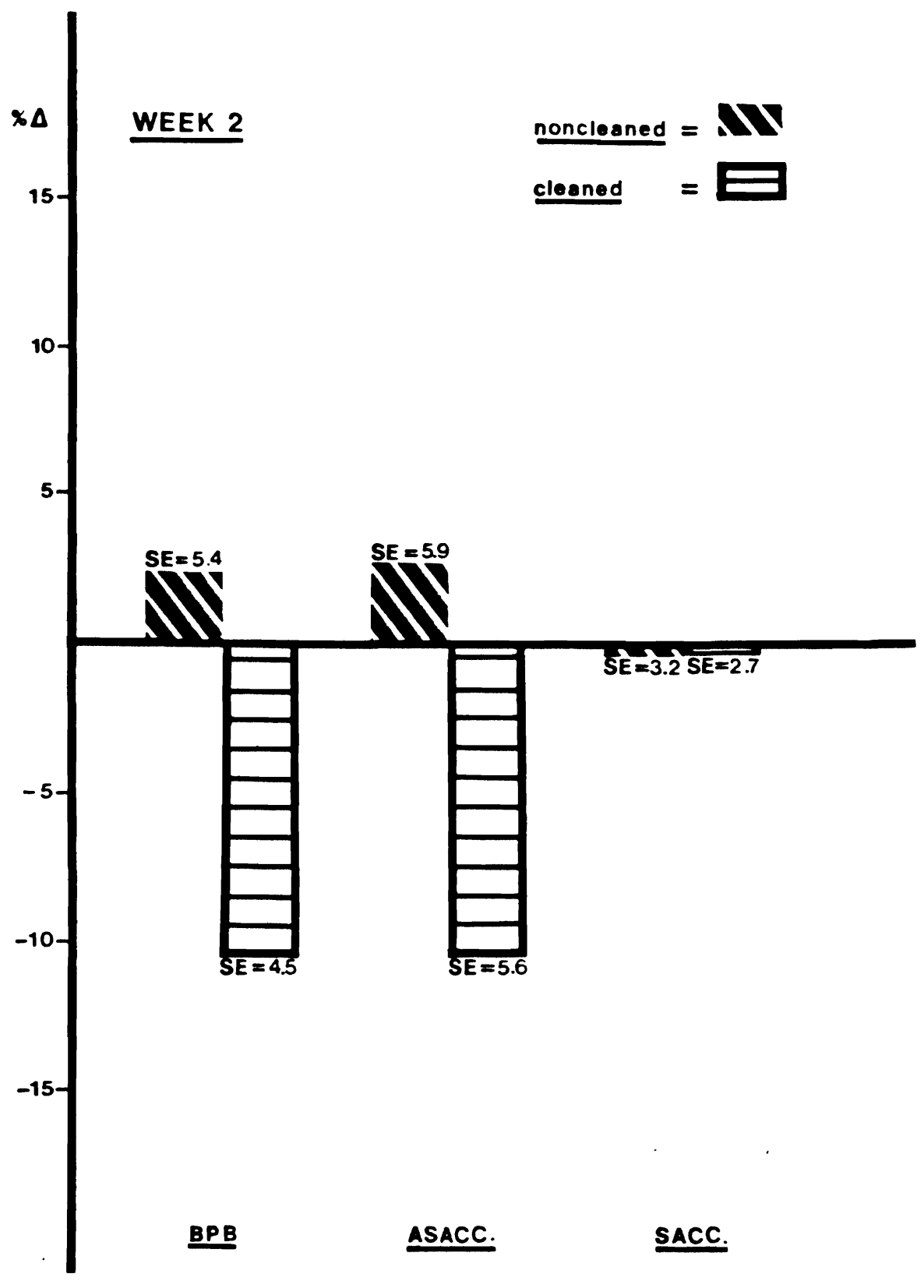




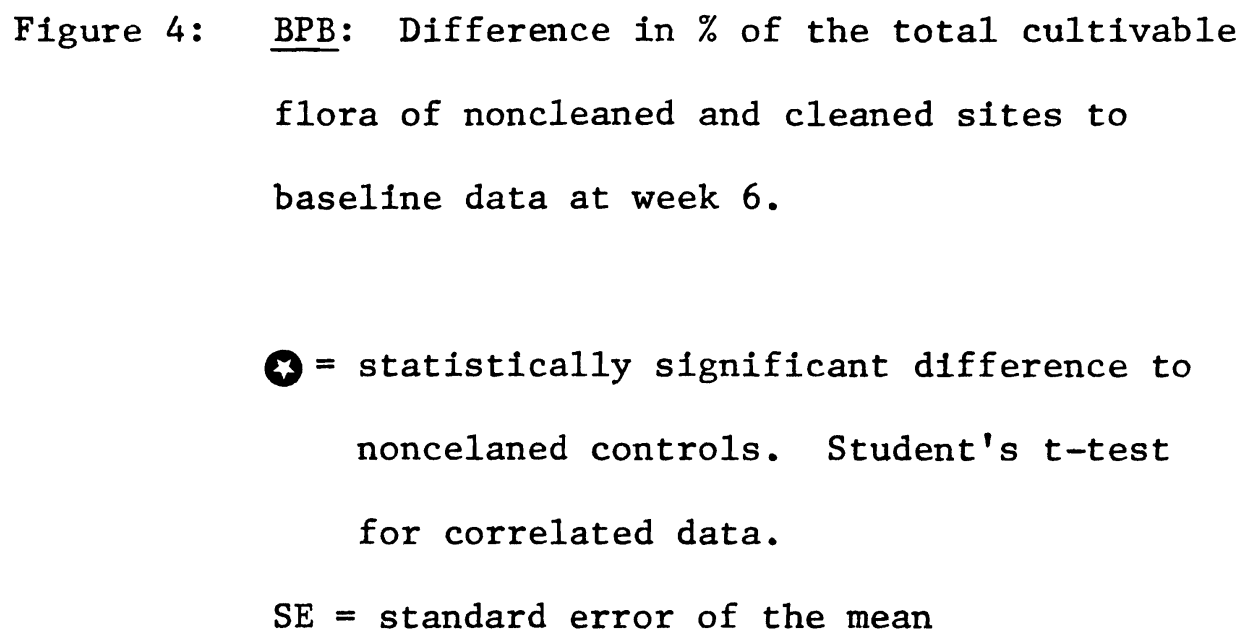




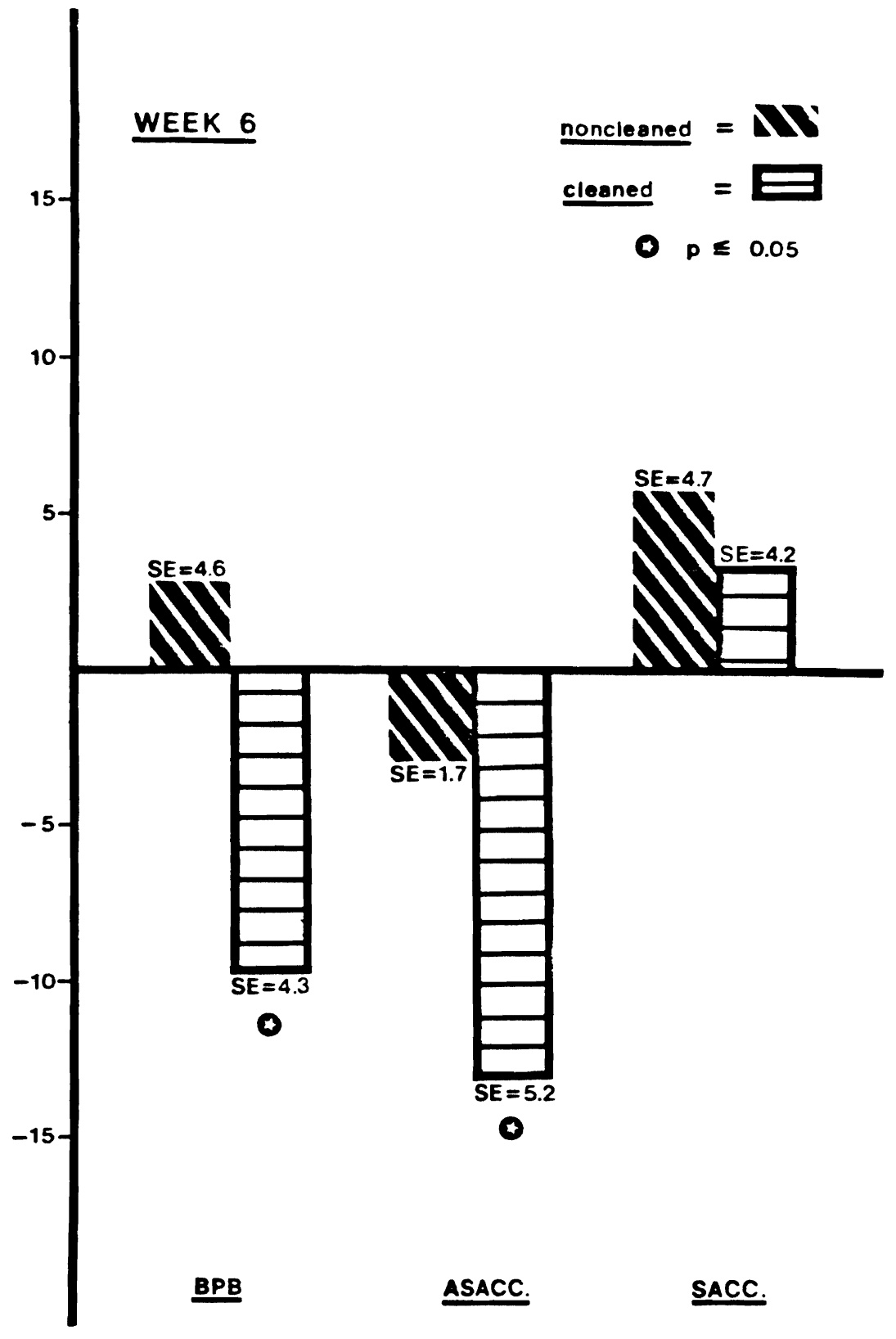


Figure 5: Spirochetes: Difference in \% of the total

organisms counted of noncleaned and cleaned sites to baseline data using phase contrast microscopy.

\# = statistically significant difference to noncleaned controls. Student's t-test for noncorrelated data.

$\mathrm{SE}=$ standard error of the mean 


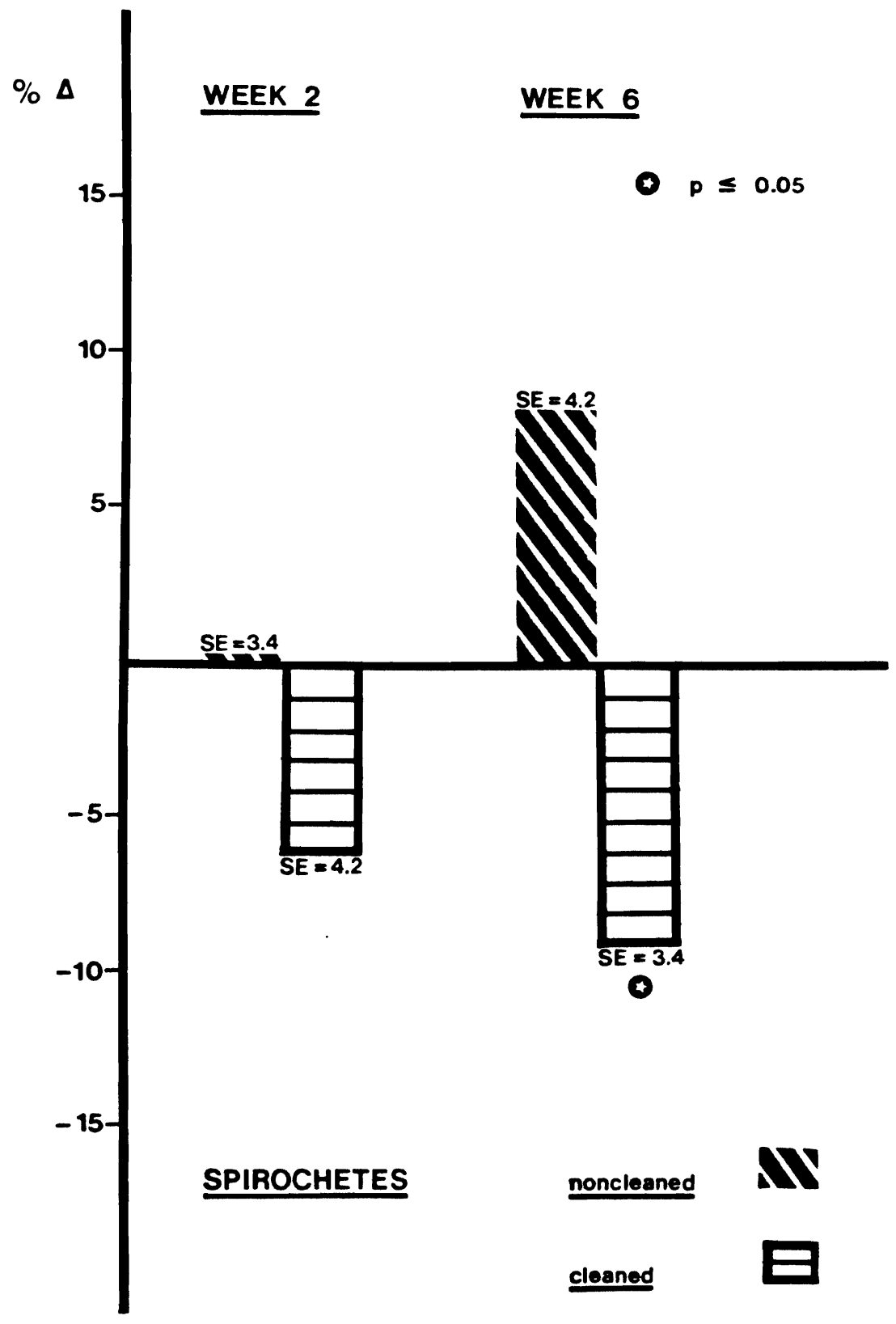


Figure 6: Scatter diagram of the differences in $\%$ of the total cultivable flora of noncleaned and cleaned sites.

Week 6 . 


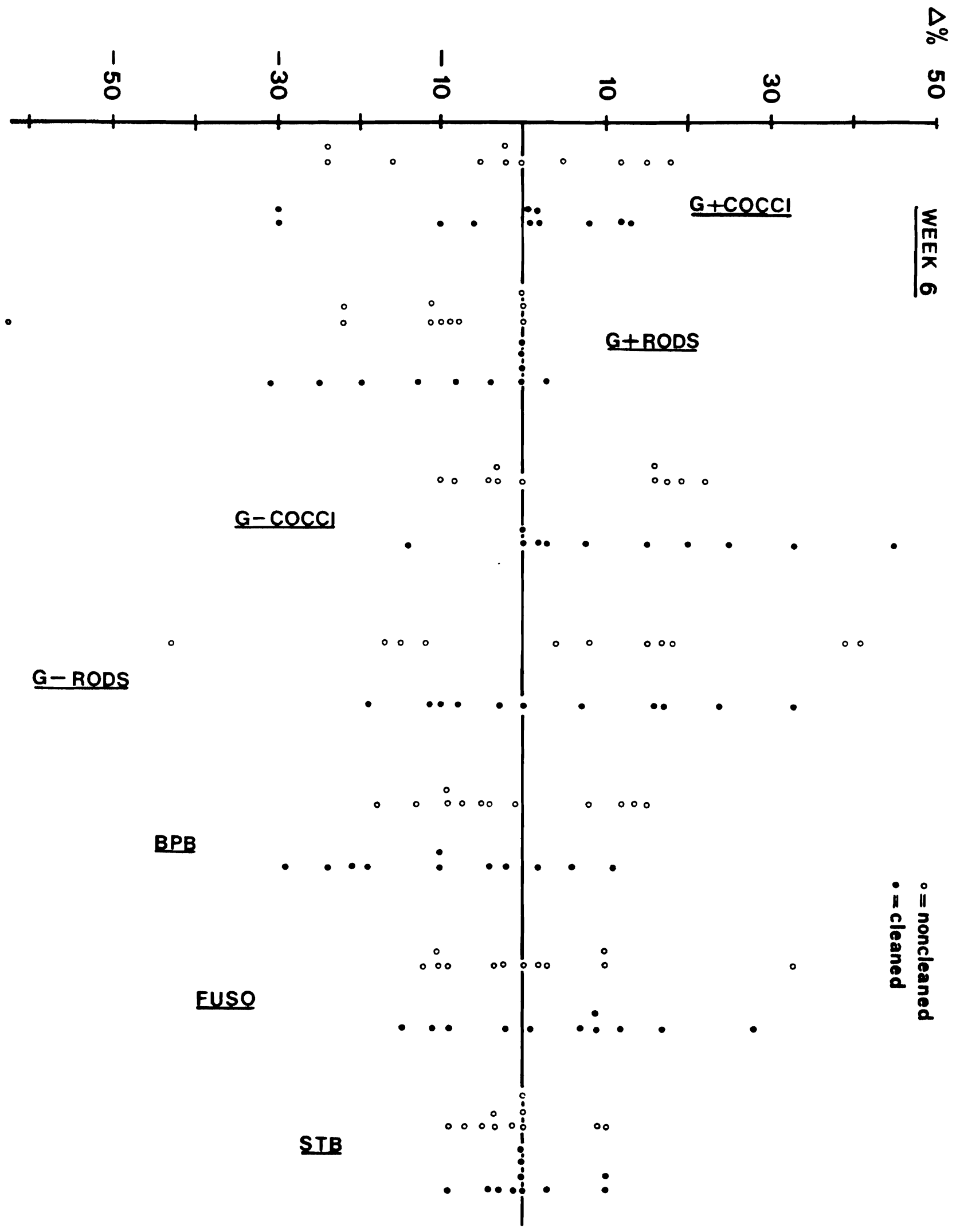


Figure 7: Scatter diagram of the differences in $\%$ of the total cultivable flora of noncleaned and cleaned sites.

Week 6 . 


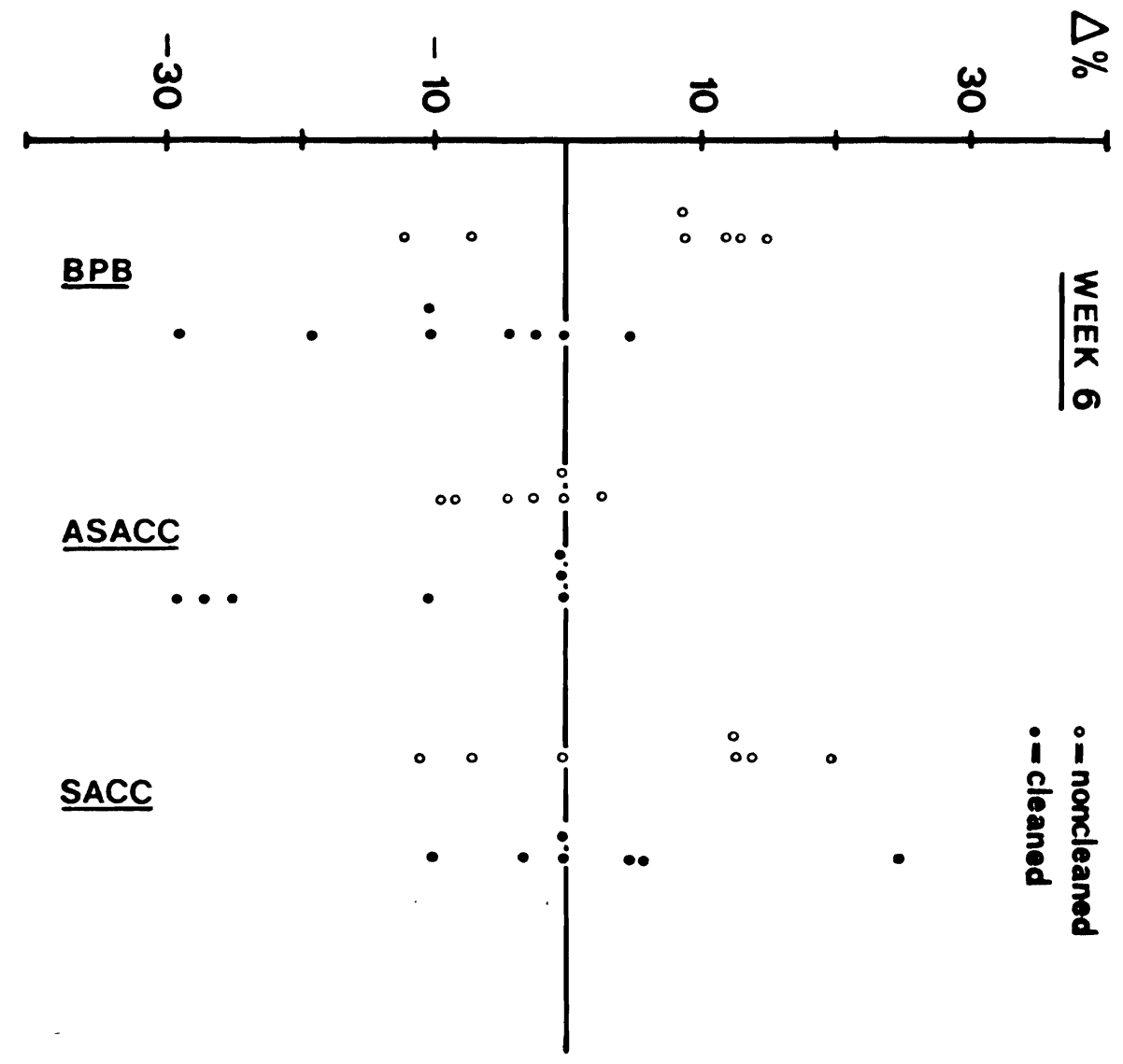


APPENDIX 


\section{Biochemical Flow Sheet}

I. Pick representative colony types from primary isolation plates (described in detail in materlal and methods section).

II. Grow in $2 \mathrm{ml}$. of $\mathrm{BAB}$.

III. Streak $1 / 2$ ETSA plate for purity check if culture in $B A B$ grew.

IV. Check ETSA cultures for purity and pick pure cultures to $\mathrm{BEN}$ and $\mathrm{BAB}$. Record growth + or - on primary isolation record.

V. As soon as growth in BEN occurs (determined by turbidity) proceed as follows:

a) add 2 to 5 drops of each BEN culture to each of 3 wells of a plastic tray. Do esculin hydrolysis, nitrate reduction and check catalase activity.

b) test indole production in the broth remaining in the BEN tube.

VI. As soon as growth in $B A B$ is determined (turbidity) proceed as follows:

a) streak aerobic blood plates (4 isolates/ plate) and incubate in candle jar.

b) smear for gram stain 4 isolates/slide. Heat fix.

c) pour part of culture into vials and freeze 
in liquid nitrogen for GLC.

d) measure $\mathrm{pH}$ of the rest of the culture in the tube with $\mathrm{pH}$ electrode.

VII. Read gram stains and evaluate biochemicals. Note all results in notebook and enter them into the computer.

VIII. After all results are entered run identification routine on the computer and examine the results that could not be identified. Evaluate which stains need GLC. 


\title{
Ingredients used for biochemical tests
}

\section{Solution A for nitrate reduction}

\author{
Nitrate solution A (soln. 1)
}

Dissolve $1.6 \mathrm{~g}$ sulfanilic acid in $200 \mathrm{ml} 5 \mathrm{~N}$ acetic actd (add $56.8 \mathrm{ml}$ glacial acetic acid to $143 \mathrm{ml}$ distilled water).

\section{Nitrate solution B (soln. 2)}

Add $1.2 \mathrm{ml}$ dimethy 1 - alphanaphthylamine to $100 \mathrm{~m} 1$ $5 \mathrm{~N}$ acetic acid.

(Add $26.8 \mathrm{ml}$ glacial acetic acid to $71.5 \mathrm{ml} \mathrm{OH}_{2} \mathrm{O}$ ).

$$
\text { Ehrlich's reagent - for indole: }
$$

Dissolve $2 \mathrm{~g}$ para-dimethylamino-benzaldehyde in $190 \mathrm{~m} 1$ of $95 \%$ ethyl alcohol and add $40 \mathrm{~m} 1$ concentrated HCL. Mix. 
Media Used

1) Enriched Trypticase Soy Agar (ETSA)

Bulk preparation (4 liters)

Potassium nitrate $20.0 \mathrm{~m} 1$

Sodium lactate syrup $4.0 \mathrm{~m} 1$

Hemin $4.0 \mathrm{~m} 1$

Distilled $\mathrm{H}_{2} \mathrm{O}$ $1972.0 \mathrm{ml}$

Yeast extract $4.0 \mathrm{~g}$

Sodium succinate $2.0 \mathrm{~g}$

Sodium formate $2.0 \mathrm{~g}$

Pour into four 1 liter bottles.

Autoclave, cool and freeze.

Each bottle (500 mls.) will make 1 liter ETSA.

1. In 2 liter flask:

Distilled $\mathrm{H}_{2} \mathrm{O}$ $443.0 \mathrm{~m} 1$

Trypticase Soy Agar $40.0 \mathrm{~g}$

Agar $4.0 \mathrm{~g}$

Mix, autoclave, $\operatorname{cool}$ to $50^{\circ} \mathrm{C}$ in water bath.

2. Add bulk preparation for 1 liter.

3. Filter sterilized ingredients:

Distilled water

Menedione

Fumarate

Lysteine $\mathrm{HC} 1$
$25.0 \mathrm{~m} 1$

$2.0 \mathrm{ml} \mathrm{ss}$

$2.0 \mathrm{ml} \mathrm{ss}$

$0.4 \mathrm{~g}$ 
Dithiothreitol

$0.1 \mathrm{~g}$

Glucose

$1.0 \mathrm{~g}$

Sodium carbonate (add last)

$0.4 \mathrm{~g}$ (5m1 ss)

Filter sterilize with 0.22 micron. Add to autoclaved portions aseptically.

4. Add aseptically $30.0 \mathrm{mls}$. sterile sheep blood.

5. Dispense $20.0 \mathrm{mls}$. per plate

2) Bulk Broth Preparation (4 liters)

Stock Mineral Solution $\#_{1}$ $300.0 \mathrm{~m} 1$

Stock Mineral Solution 非 2 w/o CaCl $300.0 \mathrm{ml}$

Hemin $4.0 \mathrm{~m} 1$

Distilled $\mathrm{H}_{2} \mathrm{O}$ $1400.0 \mathrm{ml}$

Tryptone $40.0 \mathrm{~g}$

Yeast Extract $20.0 \mathrm{~g}$

Sodium Chloride $20.0 \mathrm{~g}$

Pour equally into four 1 liter bottles. Autoclave, cool, and freeze.

Each bottle (500 mls.) makes 1 liter.

3) Basal Anaerobic Broth with Glucose (BAB)

1. In 1 liter flask:

Distilled $\mathrm{H}_{2} \mathrm{O}$ $450.0 \mathrm{~m} 1 \mathrm{~s}$.

Potassium nitrate $10.0 \mathrm{mls}$. ss

Autoclave, cool, and add to 1 bottle $(500 \mathrm{mls}$.$) of bulk$ broth preparation. 
2. Filter sterilized ingredients:

Distilled $\mathrm{H}_{2} \mathrm{O}$

$50.0 \mathrm{mls}$

Menadione

$1.0 \mathrm{~m} 1 \mathrm{ss}$

Sodium fumarate

$2.0 \mathrm{ml} \mathrm{ss}$

Glucose

$1.0 \mathrm{~g}$

Dithiothreito1

$0.2 \mathrm{~g}$

Sodium carbonate

$0.5 \mathrm{~g}(6.25 \mathrm{ml} \mathrm{ss})$

Filter sterilize with 0.22 micron. Aseptically add to autoclaved portions. Mix well and dispense in tubes.

4)

\section{Basal Esculin Nitrate Broth}

1. In 1 liter flask:

Distilled $\mathrm{H}_{2} \mathrm{O}$ $450.0 \mathrm{ml}$

Potassium nitrate $10.0 \mathrm{ml}$ ss

Esculin

$0.5 \mathrm{~g}$

Mix well, autoclave, cool to $50^{\circ} \mathrm{C}$. Add basal broth preparation (500 mls.).

2. Filter sterilized ingredients:
Distilled $\mathrm{H}_{2} \mathrm{O}$
$50.0 \mathrm{~m} 1$
Menadione
$1.0 \mathrm{~m} 1 \mathrm{ss}$
Sodium fumarate
$2.0 \mathrm{ml}$ ss
Glucose
$0.5 \mathrm{~g}$
Dithiothreitol
$0.2 \mathrm{~g}$
Sodium carbonate
$0.4 \mathrm{~g}(500 \mathrm{ml} \mathrm{ss})$
Filter sterilized with 0.22 micron. Aseptically add to autoclaved mixture. Mix well and dispense into tubes. 
5)

Reduced Transport Fluid (RTF)

Stock mineral solution $\|_{1} 1 \mathrm{w} / \mathrm{o} \mathrm{Cacl} \quad 75.0 \mathrm{ml}$

Stock mineral solution $\|^{2} \mathrm{w} / \mathrm{o} \mathrm{Cac1} \quad 75.0 \mathrm{~m} 1$

EDTA (leave out for anaerobes) $\quad 10.0 \mathrm{~m} 1$

Distilled $\mathrm{H}_{2} \mathrm{O}$

$810.0 \mathrm{ml}$ (820 if EDTA

is excluded)

Autoclave and cool. Filter sterilize the following:

Dithiothreitol

$0.2 \mathrm{~g}$

Sodium carbonate

$5.0 \mathrm{~m} 1$

Distilled $\mathrm{H}_{2} \mathrm{O}$

$25.0 \mathrm{~m} 1$

$\underline{\text { Stock Solutions }}$

Potassium nitrate

KN03

$10.0 \mathrm{~g}$

Distilled $\mathrm{H}_{2} \mathrm{O}$

$100.0 \mathrm{~m} 1$

Menadione Stock Solution $(0.5 \mathrm{mg} / \mathrm{ml})$

Menadione

$50 \mathrm{mg}$

ETOH (95\%)

$50 \mathrm{ml}$

Distilled water

$50 \mathrm{ml}$

Dissolve Menadione in ETOH, then dilute with distilled

water to $100 \mathrm{ml}$. Filter sterilize using .22 micron

filter. LIGHT SENSITIVE...STORE IN FOIL COVERED

BOTTLE IN THE REFRIGERATOR. 
Sodium Fumarate Solution (10\%)

10 grams Fumaric Acid

100 mIs. distilled $\mathrm{H}_{2} \mathrm{O}$

65 pellets $\mathrm{NaOH}$

Neutralize to $\mathrm{pH} 7.7$ with $4 \mathrm{~N}$ Sodium Hydroxide

Sodium Carbonate Stock Solution

Sodium Carbonate

Distilled water

Stock Mineral Solution 非1

Dibasic Potassium Phosphate

Distilled water

Mix well. Store in refrigerator.

Stock Mineral Solution 非

Potassium Chloride

Ammonium Sulfate

Potassium Phosphate (Monobasic)

Magnesium Sulfate

Distilled water

Mix well. Store in refrigerator.
8 grams $/ 100 \mathrm{ml}$

$100 \mathrm{~m} 1$
6 grams

$1000 \mathrm{ml}$ 


\section{$\underline{\text { References }}$}

Aranki, A., Syed, S.A., Kenney, E.B. \& Freter, R. 1969. Isolation of anaerobic bacteria from human gingiva and mouse cecum by means of a simplified glove box procedure. Applied Microbiology 17:568-576.

Ash, M.M., Gitlin, B.N. \& Smith, W.A. 1964. Correlation between plaque and gingivitis. Journal of Periodontology 35:424-428.

Axelsson, P. \& Lindhe, J. 1978. Effect of controlled oral hygiene procedures on caries and periodontal disease in adults. Journal of Clinical Periodontology 5:133-151.

Caton, J.G. \& Zander, H.A. 1975. Primate mode1 for testing periodontal treatment procedures. I. Histologic investigation of localized periodontal pockets produced by orthodontic elastics. Journal of Periodontology 46:71-77.

Chawla, T.N., Nanda, R.S. \& Kapoor, K.K. 1975. Dental prophylaxis procedures in control of periodontal disease in Kucknow (rura1) India. Journal of Periodontology 46:498-503.

Duerden, B.I., Holbrook, W.P. \& Collee, J.G. 1976. The characterization of clinically important Gram-negative anaerobic bacilli by conventional bacteriological tests. Journal of Applied Bacteriology 40:163-188.

Facklam, R.R. 1977. Physiological differentiation of viridans Streptococci. Journal of Clinical Microbiology 5:184-201.

Gibbons, R.J., Socransky, S.S. \& Kapsimalis, B. 1964. Establishment of human indigenous bacteria in germfree animals. Journal of Bacteriology 88:1316-1323.

Gibbons, R.J. \& Van Houte, J. 1975. Bacterial adherence in oral microbial ecology. Annual Review of Microbiology 29:19-44.

Greene, J.C. 1963. Oral hygiene and periodontal disease. American Journal of Public Health 53:913-922.

Greene, J.C. \& Vermillion, J.R. 1964. The simplified oral hygiene index. Journal of American Dental Association 68:7-13.

Heij1, L., Rifkin, B.R. \& Zander, H.A. 1976. Conversion of chronic gingivitis to periodontitis in squirrel monkeys. Journal of Periodontology 47:710-716.

Holdeman, L.V., Cato, E.P.\& Moore, W.E.C. 1977. Anaerobe Laboratory Manual, 4th Ed. Virginia Polytechnic Institute and State University, Blacksburg, Virginia 
Holmberg, K. \& Nord, C.E. 1975 Numerical taxonomy and laboratory identification of Actinomyces and Arachnia and some related bacteria. Journal of General Microbiology 91:17-44.

Irving, J.T., Socransky, S.S. \& Tanner, A.C.R. 1978. Histological changes in experimental perlodontal disease in rats monoinfected with gram-negative organisms. Journal of Periodontal Research $13: 326-332$.

Kenney, E.B. \& Ash, M.M. 1969. Oxidation reduction potential of developing plaque, periodontal pockets and gingival sulc1. Journal of Periodontology 40:630-633.

Kiel, R.A. 1981. The effects of localized ligature induced periodontitis on distant sites. Master of Dental Science Thesis, University of Connecticut, Farmington.

Kiel, R.A., Kornman, K.S. \& Robertson, P.B. 1981. The effects of localized ligature induced periodontitis on distant sites. (In press). Journal of Periodontal Research.

Knowles, J.W., Burgett, F.G., Nissle, R.R., Shick, R.A., Morrison, E.C., Ramfjord, S.P. 1979. Results of periodontal treatment related to pocket depth and attachment level.

Eight years. Journal of Periodontology 50:225-233.

Kornman, K.S., Caffesse, R.G. \& Nasjleti, C.E. 1980. Effect of intensive antibacterial therapy on the sulcular environment in monkeys. Part $I$. Changes in the bacteriology of the gingival sulcus. Journal of Perlodontology 51:34-38.

Kornman, K.S., Holt, S.C. \& Robertson, P.B. 1981. The microbiology of ligature-induced periodontitis in the Cynomolgus monkey. Journal of Periodontal Research 16:363-371.

Kornman, K.S., Loesche, W.J. 1980. The subgingival microbial flora during pregnancy. Journal of Perlodontal Research $15: 111-122$.

Leadbetter, E.R. \& Holt, S.C. 1974. Influence of sonification on cultivable microbiota of dental plaque. Journal of Dental Research (Special Issue) 53:Abstract 208, 106.

Lightner, L.M., O'Leary, T.J., Drake,R.B., Crump, P.P.\& Allen, M.F. 1971. Preventive periodontal treatment procedures. Journal of Periodontology 42:555-561.

Lindhe, J. \& Ericsson, I. 1978. Effect of ligature placement and dental plaque on periodontal tissue breakdown in the dog. Journal of Periodontology 49:343-350. 
Lindhe, J., Hamp, S.E. \& Löe, H. 1973. Experimental periodontitis in the beagle dogs. Journal of Periodontal Research 8:1-10.

Lindhe, J., Hamp, S.E. \& Löe, H. 1975. Plaque induced periodontal disease in beagle dogs. A 4-year clinical, roentgenographical and histological study. Journal of Periodontal Research $10: 243-255$.

Listgarten, M.A. 1976. Structure of the microbial flora associated with periodontal health and disease in man. A 11 ght and electron microscopic study. Journal of Periodontology 47:1-18.

Listgarten, M.A., Lindhe, J., Hellden, L. 1978. Effect of tetracycline and/or scaling on human periodontal disease. Journal of Clinical Periodontology 5:246-271.

Lôe, H. \& Schiött, C.R. 1970. The effect of suppression of the oral microflora upon the development of dental plaque and gingivitis. In: Dental Plaque, E.S. Livingstone LTD. Pp. 247-255.

Löe, H. \& Silness, J. 1963. Periodontal disease in pregnancy. I. Prevalence and severity. Acta Odontologica Scandinavica $21: 533-551$.

Löe, H., Theilade, E. \& Jensen, S.B. 1965. Experimental gingivitis in man. Journal of Periodontology 36:177-187.

Loesche, W.J. 1968. Importance of nutrition in gingival crevice microbial ecology. Periodontics 6:245-249.

Loesche, W.J., Hockett, R. \& Syed, S.A. 1972. The predominant cultivable flora of tooth surface plaque removed from institutionalized subjects. Archives of Oral Biology 17:1311-1325.

Loesche, W.J. \& Nafe, D. 1973. Reduction of supragingival plaque accumulations in institutionalized Down's Syndrome patients by periodic treatment with topical Kanamycin. Archives of Oral Biology 18:1131-1143.

Lövdal, A., Arno, A., Schei, 0.\& Waerhaug, J. 1961. Combined effect of subgingival scaling and controlled oral hyglene on the incidence of gingivitis. Acta Odontologica Scandinavica $19: 537-555$.

Lövdal, A., Arno, A. \& Waerhaug, J. 1958. Incidence of clinical manifestations of periodontal disease in light of oral hygiene and calculus formation. Journal of American Dental Association 56:21-33. 
Manganie11o, A.D., Socransky, S.S., Smith, C., Propas, D., Oram, V. \& Dogon, I.L., 1977. Attempts to increase viable counts recovery of human supragingival dental plaque. Journal of Periodontal Research 12:107-119.

Miller, W.D. 1980. Microorganisms of the human mouth. S.S. White and Co., Philadelphia. pp. 333.

Morrison, E.C., Lang, N.P., Löe, H. \& Ramfjord, S.P. 1979. Effects of repeated scaling and root planing and/or controlled oral hygiene on the periodontal attachment level and pocket depth in beagle dogs. Journal of Periodontal Research 14:428-437.

Mousques, T., Listgarten, M.A. \& Stoller, H.H. 1980. Effect of sampling on the composition of the human subgingival microbial flora. Journal of Periodontal Research 15:137-143.

Newman, M.G.\& Socransky, S.S. 1977. Predominant cultivable microblota in periodontosis. Journal of Periodontal Research $12: 120-128$.

Nyman, S., Lindhe, J. \& Rosling, B. 1977a. Periodontal surgery in plaque infected dentitions. Journal of Clinical Periodontology 4:240-249.

Nyman, S., Rosling, B. \& Lindhe, J. 1975. Effect of professional tooth cleaning on healing after periodontal surgery. Journal of Clinical Periodontology 2:80-86.

Palenstein-Helderman, W.H., van 1975. Total viable count of Vibrio (Campylobacter) sputorum, Fusobacterium nucleatum, Selenomonas sputigena, Bacteroides ochraceus and Veillonella in the inflamed human gingival crevice. Journal of Periodontal Research 10:294-304.

Ramjford, S.P. 1961. Survey of the periodontal status of boys 11 to 17 years old in Bombay, India. Journal of Periodontology $32: 237-248$.

Ramfjord, S.P., Knowles, J.W., Nissle, R.R., Burgett, F.G. \& Schick, R.A. 1975. Results following three modalities of periodontal therapy. Journal of Periodontology 46:522-526.

Ritz, H.L. 1967. Microbial population shifts in developing human dental plaque. Archives of Oral Biology 12:1561.

Russe11, A.L. 1956. A system of classification and scoring for prevalence surveys of periodontal disease. Journal of Dental Research 35:350-359. 
Rovin, S., Costich, E. \& Gordon, H. 1966. The influence of bacteria and irritation in the initiation of periodontal disease in germ-free and conventional rats. Journal of Periodontal Research 1:193-203.

Sche1, 0., Waerhaug, J., Lövda1, A. \& Arno, A. 1959. Alveolar bone loss related to oral hygiene and age. Journal of Periodontology 30:7-16.

Schroeder, H.E. \& Lindhe, J. 1975. Conversion of established gingivitis into destructive periodontitis. Archives of Oral Biology 20:775-782.

Schroeder, H.E. \& Lindhe, J. 1980. Conditions and pathological features of rapidly destructive, experimental periodontitis in dogs. Journal of Periodontology 51:6-19.

Silness, J. \& Löe, H. 1964. Periodontal disease in pregnancy. II. Correlation with oral hygiene and periodontal condition. Acta Odontologica Scandinavica 22:121-135.

Slots, J. 1976. The predominant cultivable organisms in juvenile periodontitis. Scandinavian Journal of Dental Research 84:1-10.

Slots, J. 1977. The predominant cultivable microflora of advanced periodontitis. Scandinavian Journal of Dental Research 85:114-121.

Slots, J. \& Gibbons, R.J. 1978. Attachment of Bacteroldes melaninogenicus supsp. asaccharolyticus to oral surfaces and its possible role in colonization of the mouth and of periodontal pockets. Infection and Immunity 19:254-264.

Slots, J. \& Hausman, E. 1979. Longitudinal study of experimentally induced periodontitis in Macaca arctoides: Relationship between microflora and alveolar bone loss. Infection and Immunity 23:260-269.

Spiegel, C.A., Hayduk, S.E., Minah, G.E.\& Krywolap, G.N. 1979. Black pigmented Bacteroides from clinically characterized periodontal sites. Journal of Periodontal Research $14: 376-382$.

Suomi, J.D., Greene, J.C., Vermillion, J.R., Doyle, J., Chang, J.J. \& Leatherwood, E.C. 1971. The effect of controlled oral hygiene procedures on the progression of periodontal disease in adults: Results after third and final year. Journal of Periodontology 42:152-160. 
Syed, S.A. \& Loesche, W.J. 1978. Efficlency of Kontes ultrasonic cell disrupter in the dispersion of dental plaque and pure cultures of oral flora. Journal of Dental Research 57: Abstract 982 .

Syed, S.A. \& Loesche, W.J. 1978. Bacteriology of human experimental gingivitis: Effect of plaque age. Infection and Immunity 21:821-829.

Syed, S.A. Svanberg, M. \& Svanberg, G. 1980. The predominant cultivable dental plaque flora of beagle dogs with gingivitis. Journal of Periodontal Research. 15:123-136.

Tal, M. 1981. Periodontal disease and oral hygiene described by Antonio Van Leeuwenhoek. Journal of Periodontology 51:668-669.

Tanner, A.C.R., Haffer, C., Bratthal, G.T., Visconti, R.A.\& Socransky, S.S. 1979. A study of the bacteria associated with advancing periodontitis in man. Journal of Clinical Periodontology 6:278-307.

Waerhaug, J. 1977. Subgingival plaque and loss of attachment in periodontosis as evaluated on extracted teeth. Journal of Periodontology 48:125-130.

Waerhaug, J. 1978. Healing of the dento-epithellal junction following subgingival plaque control. I. As observed in human biopsy material. Journal of Periodontology 49:1-8.

White, D. \& Mayrand, D. 1981. Association of oral Bacteroides with gingivitis and adult periodontitis. Journal of

Periodontal Research 16:259-265. 